\title{
Clinical Controversies in Aerosol Therapy for Infants and Children
}

\author{
Robert M DiBlasi RRT-NPS FAARC
}

\author{
Introduction \\ Differences in Aerosol Drug Delivery Between Pediatric and Adult Patients \\ Clinical Considerations and Age-Appropriate Administration Practices \\ Patient-Related Factors \\ Aerosol Device Selection \\ Interface Selection \\ Clinical Controversies \\ Drug Delivery in Crying Versus Resting Infants \\ Blow-By \\ Jet Nebulizer Versus Pressurized Metered-Dose Inhaler/Spacer for Bron- \\ chodilators \\ Continuous Nebulization \\ Noninvasive Respiratory Support \\ Optimizing Nebulizer Performance During Mechanical Ventilation \\ Conclusions
}

\begin{abstract}
Pediatric patients are different from adult patients with respect to airway anatomy and breathing patterns. They are also incapable of following commands and often reject breathing treatments. For these reasons, aerosol drug delivery is one of the most technically challenging aspects for clinicians providing respiratory care to young children. Improvements in nebulizer technology have provided better delivery options for pediatric patients. This review highlights research related to pediatric nebulizer and interface devices and how they can be used to provide the safest and most efficient treatments with the array of treatment delivery options. Also addressed are clinical controversies and debates in pediatric aerosol science, including drug delivery in crying versus resting infants, pressurized metered-dose inhalers and small-volume nebulizers for bronchodilator administration, continuous nebulization, noninvasive drug delivery options, and optimization of nebulizer performance during infant and large pediatric conventional and high-frequency ventilation.

Key words: aerosol delivery; pediatric; neonatal; noninvasive ventilation; inhaled drugs. [Respir Care 2015;60(6):894-916. (C) 2015 Daedalus Enterprises]
\end{abstract}

\section{Introduction}

Aerosolized drugs are frequently administered to pediatric patients to alleviate bronchospasm, reduce airway

\footnotetext{
Mr DiBlasi is affiliated with the Department of Pediatrics, Seattle Children's Hospital, and the Center for Developmental Therapeutics, Seattle Children's Hospital Research Institute, Seattle, Washington.
}

Mr DiBlasi presented a version of this paper at the 53rd RESPIRATORY inflammation, facilitate mucus clearance, improve pulmonary blood flow, and prevent or treat infection. The majority of aerosolized drugs that are provided to pediatric patients are used off-label, meaning that: (1) the drug either has not been cleared for aerosolization, (2) it has been

\footnotetext{
CARE Journal Conference, “Aerosol Drug Delivery in Respiratory Care," held June 6-7, 2014, in St Petersburg, Florida.

Mr DiBlasi has disclosed relationships with Dräger, United Therapeutics, Vapotherm, and Ikaria.
} 
cleared in a different patient population (adults), or (3) it is being used with a different delivery device than that cleared by the United States FDA. Drug manufacturers very seldom perform dose range and efficacy studies in infants and children, and doses may or may not be adjusted based on weight. Nonetheless, many of these drugs are life-saving or have had some impact on outcomes in patients.

On the surface, drug delivery to patients appears simple and safe and is often perceived as effective because the nebulizer produces an aerosol plume and the patient is inhaling. However, it is likely that very little of the drug is actually delivered to the targeted site (ie, peripheral airways). Assessing the efficacy of a breathing treatment can be confusing to pediatric clinicians because there is virtually no available objective measurement to determine clinical efficacy, especially in younger children. There are many different challenges and complex issues associated with aerosol delivery in children that are not present in adults. Where definitive data are lacking for children, aerosol practices have been derived by extrapolating data from adult studies. Novel in vivo and in vitro pediatric studies have shed new light on some of the major clinical controversies that have been at the center of debate among clinicians and researchers for years.

Over the last few decades, a proliferation of novel respiratory support devices have been introduced to the clinical arenas. This has resulted in many different treatment delivery options. In the continuum of care for critically ill children, it is not uncommon for a patient to receive multiple inhaled drugs with several different delivery options during the course of a hospital stay. These options include aerosol masks or mouthpieces, heated high-flow nasal cannulas, noninvasive positive-pressure devices, and/or mechanical ventilators. Clinicians have found ways to adapt to this dynamic clinical environment by integrating nebulizers into ventilators and oxygen delivery systems, often with very little evidence to support safe or efficacious use in pediatric patients. The purpose of this timely review is to provide clinicians with an in-depth review of the pediatric aerosol literature with an emphasis on patient safety and outcomes, clinical controversies, and novel advances in aerosol treatment approaches.

Correspondence: Robert M DiBlasi RRT-NPS FAARC, Center for Developmental Therapeutics, Seattle Children's Hospital Research Institute, 1900 Ninth Avenue North, Seattle, WA 98101. E-mail: robert.diblasi@seattlechildrens.org.

DOI: $10.4187 /$ respcare. 04137

\section{Differences in Aerosol Drug Delivery Between Pediatric and Adult Patients}

Pulmonary deposition of aerosol particles is generally lower in pediatric patients than in adults, with infants receiving significantly smaller amounts of drug in the peripheral airways compared with older pediatric patients. This is especially true in children $<3-4$ y old and even more so in infants $<18$ months old, who may have a large majority of the drug deposited in the upper airways. ${ }^{1}$

In vivo comparative studies evaluating aerosol deposition within different regions of the human respiratory tract in infants, young children, and adults are lacking. A recent study $^{2}$ evaluating drug deposition using a 3-dimensional model rendering from computed tomography scans of healthy infants, children, and adults showed that substantial variability exists in airway morphology, air-flow dynamics, and regional aerosol deposition among subjects of different ages.

Poor drug delivery in children can be attributed to rapid and often variable breathing frequencies, low tidal volumes $\left(\mathrm{V}_{\mathrm{T}}\right)$, and high resistance due to the small crosssectional diameter of the airways. High resistance and short inspiratory time result in short residence time for an aerosol to deposit in the airways. Inspiratory-expiratory ratios are shorter in pediatric patients compared with adult patients, resulting in potentially greater drug loss during exhalation, especially when using a device that nebulizes drug throughout the entire respiratory cycle. Some of these effects may be offset by low inspiratory flow in relation to the constant and relatively high $(6-8 \mathrm{~L} / \mathrm{min})$ flow of some nebulizers, which may result in less air entrainment from the surrounding environment. ${ }^{1}$ As such, each breath may deliver a proportionally higher dose (more concentrated aerosol bolus) per breath to young children compared with adults.

Infants are considered obligate nasal breathers due to the proportionally large tongue size to small oral volume and the proximity of the larynx and epiglottis to the base of the tongue. Younger patients have smaller nostrils, a shorter turbinate region, a narrower nasopharynx, a narrower pharynx-larynx, and a relatively larger anatomic dead space than do adults, making drug delivery a challenge. ${ }^{2}$ Nasal airway resistance accounts for nearly half of the respiratory resistance in healthy infants, ${ }^{3}$ and turbulent flow in this region likely accounts for a large amount of impactive drug loss in the upper airways. Interestingly, nasal breathing for aerosol delivery to the distal airways is similar to, or more efficient than, mouth breathing in infant and toddler models, ${ }^{4}$ contrary to what is observed in older children and adults, who have more well-developed nasal turbinates and less complex airway structures. However, infants are extremely vulnerable to spontaneous nasal obstruction ${ }^{5}$ from secretions, inflammation, or nasal 
airway interfaces, placing them at another unique disadvantage for drug delivery.

Perhaps the largest challenge with drug delivery is related to behavioral and emotional aspects that are unique to pediatric patients. Infants and toddlers do not have the cognitive or physical abilities to coordinate breathing efforts with the treatment. Many will not accept a mouthpiece treatment, and a tightly fitting aerosol mask is poorly tolerated, usually resulting in squirming, thrashing, and crying.

Despite the many limitations of inhaled drug delivery in children, in vivo studies have shown that measureable quantities of drug can be delivered to the lungs of these small patients. Experimental data obtained from in vivo studies during spontaneous unassisted breathing have demonstrated that $<3 \%$ of the nominal dose of aerosolized drugs is delivered to the lungs of infants, ${ }^{6-9} 1.6-4.4 \%$ to those of young children, ${ }^{8,10,11}$ and $10-58 \%$ to those of adults. ${ }^{12-14}$ The majority of these studies were conducted using oldergeneration jet nebulizers and spacers, and in vivo measurements in patients using newer drug delivery devices and techniques are virtually nonexistent due to concerns related to the expense and risk of using inhaled radiolabeled isotopes in children. Inconsistencies in scintigraphy methods used to provide qualitative and quantitative data on aerosol drug deposition in the lungs and lack of clinical monitoring also are problems in this population. ${ }^{15}$

Although drug delivery efficiency appears low in pediatric patients, the lung dose may be appropriate when the weight-adjusted dose is considered. As such, the weightadjusted dose is similar between pediatric and adult patients. ${ }^{16}$ This does not imply similar risk or treatment efficacy between these vastly different patient populations. Additionally, pharmacodynamics and pharmacokinetics of inhaled agents are poorly understood in pediatric patients.

\section{Clinical Considerations and Age-Appropriate Administration Practices}

There are many clinical and age-appropriate factors that clinicians and other caregivers need to consider when choosing an appropriate aerosol delivery device or strategy in children. An aerosol strategy, aerosol device, and delivery interface should be chosen based on: (1) availability of high-quality evidence obtained from human, animal, or bench studies; (2) device/interface efficiency; (3) ability of the patient to tolerate and coordinate respiratory effort with drug delivery; (4) patient preference; (5) cost of drug delivery; (6) whether the drug is approved to be used with a certain device or not; and (7) whether the device can be used safely with the form of respiratory support that the patient is receiving. ${ }^{17,18}$
Table 1. Age Guidelines for Use of Aerosol Delivery Device Types

\begin{tabular}{lc}
\hline \hline \multicolumn{1}{c}{ Aerosol Device and Interface } & Age \\
\hline Small-volume nebulizer with mask or hood & Infant \\
Small-volume nebulizer with mask & $\leq 3 \mathrm{y}$ \\
Small-volume nebulizer with mouthpiece & $\geq 3 \mathrm{y}$ \\
pMDI with valved holding chamber/spacer and mask & $<4 \mathrm{y}$ \\
pMDI with valved holding chamber/spacer & $\geq 4 \mathrm{y}$ \\
DPI & $\geq 4 \mathrm{y}$ \\
MDI & $\geq 5 \mathrm{y}$ \\
Breath-actuated MDI (eg, Autohaler) & $\geq 5 \mathrm{y}$ \\
Breath-actuated nebulizer & $\geq 5 \mathrm{y}$ \\
& \\
\hline From Reference 17. & \\
pMDI = pressurized metered-dose inhaler & \\
DPI = dry powder inhaler & \\
\hline
\end{tabular}

\section{Patient-Related Factors}

In addition to aerosol device selection, clinicians serve a vital role in educating patients and caregivers about nebulizer therapy in a variety of settings. This can ultimately have a major impact on drug delivery to the lungs and reduce infection risk. The quality of education or instruction may mean the difference between a patient being readmitted to the hospital or not. As such, health-care providers, patients, and family members must demonstrate competency with the proper technique and instruction of aerosol delivery systems. ${ }^{17}$ Differences in the physical and cognitive abilities and age of patients to effectively use a mouthpiece or mask seal or coordinate breathing efforts typically guide selection of the device and interface that will be used to deliver drug (Table 1).

Clinicians within the health-care setting must be able to recognize ways to optimize drug delivery that go beyond placing the device on a patient. Promoting a strong cough in patients who have retained secretions, coaching deep breathing, and sitting patients upright during a treatment are a few simple solutions that may promote better drug delivery to the lung. It is also important to assess patients' pulmonary condition to see if they are responding to their inhaled medication regimen. This can be done using spirometry in older patients, with fewer choices in young children. If the patient does not appear to be responding to the treatment, then using a new delivery system may be an option or discontinuing the treatment may be more beneficial than exposing patients to unnecessary adverse effects from the drugs.

Clinicians must be willing to listen to patients and family members when they prefer a particular treatment option. Acceptance of a treatment may ultimately reflect adherence and potentially better efficacy. Finally, clinicians need to consider all of the potential delivery options used when combining nebulizers with different pediatric respi- 
ratory support devices. They should never assume that a particular nebulizer treatment or strategy given with one treatment modality (eg, aerosol mask) will provide similar therapeutic effects or safety as another modality (eg, ventilator). Clinicians should always use a device that delivers drugs safely and efficiently while minimizing potential risks that can arise due to infection, airway occlusion, and inadvertent pressurization of the lungs; equipment malfunction; and poor triggering of different ventilator devices.

\section{Aerosol Device Selection}

There is currently no clinical consensus guiding the decision for aerosol device selection in most children. The vast majority of nebulizers used in adults are also used in children. Optimal particle size for most inhaled medications to achieve deposition in the periphery of the lung is $1-5 \mu \mathrm{m} .{ }^{18}$ Thus, an aerosol device should be chosen based on whether it can provide particles within this range. Aerosol devices that produce highly variable drug delivery or particles of $>5 \mu \mathrm{m}$ should be avoided because they may be more likely to deposit in children's upper airways, resulting in systemic absorption and potentially greater adverse effects (tachycardia).

Bronchodilator delivery with jet nebulizers and pressurized metered-dose inhalers (pMDIs) has been shown to be very low $(0.33 \%$ and $0.13 \%$, respectively) in infants with respiratory distress. ${ }^{6}$ Infants with viral bronchiolitis represent a large subset of these patients admitted to pediatric hospitals. Bronchodilators have not been shown to be effective in the routine management of bronchiolitis, ${ }^{19}$ and it is not known whether the lack of bronchodilator effect observed is related to poor deposition from airway obstruction or the fact that inefficient nebulizers were used in these early studies. Moreover, objective studies to measure bronchodilator response in this population require sedation and are costly and very difficult to perform. Future studies using novel pediatric-specific pMDI/spacers and vibrating mesh nebulizers would be useful to determine bronchodilator response in infants with bronchiolitis and other infant lung diseases. Evaluating nebulizer efficiency is important for delivery of not only bronchodilators but also other inhaled drugs that are delivered to infants and small children, including pulmonary vasodilators, corticosteroids, antibiotics, and hypertonic saline.

The most common delivery devices used with pediatric patients include pMDIs with valved holding chambers (pMDI/VHC) or spacers, dry powder inhalers, jet or gaspowered nebulizers, breath-actuated nebulizers, ultrasonic nebulizers, vibrating mesh nebulizers, and small-particle aerosol generators. The vibrating mesh nebulizer and pMDI/VHC represent 2 nebulizer devices that have revolutionized drug delivery in children due to ease of use, patient acceptance, and ability to integrate into a ventilator system. They are also some of the most expensive forms of drug delivery. The most common nebulizers used in the pediatric clinical setting are small-volume nebulizers, including jet, vibrating mesh, and breath-actuated nebulizers. These nebulizers can produce most forms of medication, whereas a pMDI/VHC cannot. An in-depth discussion of $\mathrm{pMDI} / \mathrm{VHC}$ and interfaces is provided in the clinical controversies section.

The dry powder inhaler and breath-actuated nebulizer can be used in many pediatric patients but are generally reserved for patients who are able to generate sufficient force to activate a valve that releases the medication. Breathactuated nebulizers are particularly attractive because, unlike other nebulizer devices, they nebulize only during inhalation, which reduces aerosol waste but extends the treatment time. Ultrasonic nebulizers and small-particle aerosol generators are typically approved to deliver specialty medications and are generally bulky or large, so they are not used frequently in the clinical setting.

Disposable jet nebulizers are simple to use and relatively inexpensive, but drug delivery is extremely inefficient and variable owing to the highly variable particle size and large residual volume of drug left behind in the nebulizer cup at the end of the treatment. ${ }^{20}$ In some cases, residual loss can account for nearly $50-75 \%$ of the drug placed in the nebulizer. ${ }^{21,22}$ Moreover, there are differences in drug delivery related to nebulizer flow and gas composition and whether the device is being powered by a compressor or pressurized gas source. ${ }^{23}$ Integrating jet nebulizers into a ventilator circuit or respiratory support device may inadvertently increase pressure and volume and affect triggering due to the additional flow.

The vibrating mesh nebulizer is unique in that it does not require a gas source, making it extremely safe and effective during noninvasive or invasive mechanical ventilation. The high efficiency of this nebulizer is based on a very low residual drug volume $(\sim 0.1 \mathrm{~mL})$ remaining in the medication reservoir following a treatment. Several investigators have evaluated differences in drug delivery between different small-volume nebulizers. In one study, ${ }^{24}$ bronchodilator drug delivery by a breath-actuated nebulizer (AeroEclipse, Monaghan Medical, Plattsburgh, New York) and 2 other jet nebulizers equipped with face masks was compared in a spontaneously breathing toddler airway/lung model. The breath-actuated nebulizer configured with breath activation on provided less inhaled drug mass $(<1 \%)$ than the other devices $(5.7-10.8 \%)$. The AeroEclipse requires a tight-fitting mask for effective treatment and may not be preferable in small children because the generated flows are too low to activate the one-way valve to consistently provide aerosolized drug to the patient, and the treatment time could be upwards of $40 \mathrm{~min}$. Although the manufacturer suggests manual 
activation with this breath-actuated nebulizer when the patient cannot open the valve appropriately, a significant lag time may prevent small patients from receiving drug during inhalation.

Jet nebulizers were found to provide greater drug delivery compared with vibrating mesh nebulizers in a lung model using different-size realistic pediatric airway models affixed with an array of different airway interfaces. ${ }^{23} \mathrm{In}$ a number of testing conditions with the vibrating mesh nebulizers, there was no detectable drug on the test lung filter because supplemental oxygen flow is required to facilitate the movement of the aerosol plume toward the patient. Another study ${ }^{25}$ was designed to compare drug delivery between jet and vibrating mesh nebulizers using 3 different mask interfaces in a spontaneously breathing pediatric lung model. There were no differences in the amount of drug delivered to a filter between 2 commonly used vented aerosol masks, but the delivery was nearly 2 -fold greater with the vibrating mesh nebulizer than the jet nebulizer when a valved aerosol mask was used.

An investigational next-generation vibrating mesh nebulizer (eFlow, PARI Medical, Starnberg, Germany) designed specifically for premature infants showed nearly 20 -fold greater drug delivery to a neonatal model compared with jet nebulizers and pMDIs/VHCs. ${ }^{26}$ This may have important clinical implications for patients who are receiving aerosolized artificial surfactant or who do not respond to bronchodilators using standard approaches (ie, bronchiolitis). Although these findings are interesting from a research standpoint, it is unreasonable from a cost standpoint to suggest vibrating mesh or ultrasonic nebulizers over jet nebulizers for routine delivery of drugs (ie, bronchodilators).

\section{Interface Selection}

The most effective inhaled drug treatment in older spontaneously breathing pediatric patients has been shown to be via a mouthpiece. ${ }^{26}$ In fact, a mouthpiece may provide twice as much drug as a simple aerosol face mask. ${ }^{25} \mathrm{~A}$ slow deep inhalation followed by an occasional breathhold may also help improve aerosol delivery to the lungs. Most infants do not have the ability to open the mouth on command and close it around a nebulizer mouthpiece to get an adequate seal, nor do they have the ability to breathe deeply and hold their breath on command. In the event that a mouthpiece cannot be used with a nebulizer, a properly fitted mask should be used in infants, toddlers, or uncooperative pediatric patients. Optimal mask/face seal is important in maximizing aerosol delivery, and all efforts should be made to avoid leaks by providing a tight fit (Fig. 1). ${ }^{10,27-30}$ Minimizing leaks not only prevents the drug from entering the atmosphere and provides more drug to the
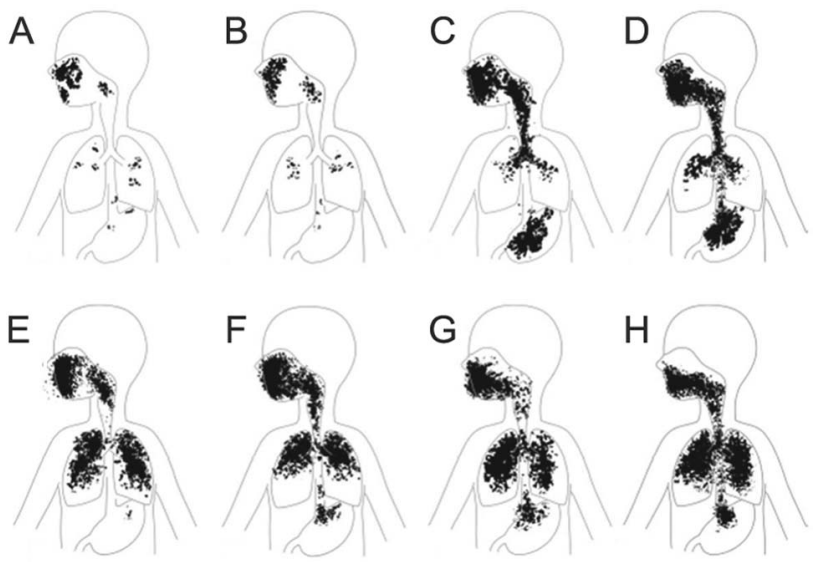

Fig. 1. Drug deposition of radiolabeled salbutamol in a young child. A: Inhaling with a pressurized metered-dose inhaler (pMDI)/spacer through a loosely fitted face mask. B: Inhaling with a nebulizer through a loosely fitted face mask. C: Inhaling with a pMDI/spacer through a tightly fitted face mask and screaming during inhalation. $D$ : Inhaling with a nebulizer through a tightly fitted face mask and screaming during inhalation. $\mathrm{E}$ and $\mathrm{F}$ : Inhaling with a pMDI/spacer through a tightly face mask and quietly inhaling. $\mathrm{G}$ and $\mathrm{H}$ : Inhaling with a nebulizer through a tightly fitted face mask and quietly inhaling. From Reference 10, with permission.

lung but also prevents the drug from getting to the face and eyes and causing irritation to the patient. ${ }^{10}$

The face mask design is an important aspect of medication delivery in smaller children, regardless of the nebulizer device being used. ${ }^{31}$ The mask should be soft, warm, and constructed with flexible material. ${ }^{32}$ Generally, smaller patients require smaller masks because with less dead space, the more likely it is that a greater proportion of the dose coming from the device will be inhaled into the lungs..$^{33,34}$ This is especially true when using vibrating mesh nebulizers and pMDIs/VHCs or other devices that do not add gas to the system. Mask design is particularly important in gas-powered jet nebulizers because flows range from 6 to $10 \mathrm{~L} / \mathrm{min}$, resulting in high-flow velocities, particle inertia, and deposition within the mask.

Several in vitro studies showed that a front-loaded mask (Bubbles the Fish II mask, PARI Respiratory Equipment, Midlothian, Virginia) provided greater aerosol mass to a lung model and lower eye and facial aerosol deposition compared with bottom-loaded mask designs. ${ }^{35-38}$ One study ${ }^{39}$ showed the opposite effect in a pediatric lung model, wherein a standard bottom-loaded aerosol mask resulted in greater drug delivery than a frontloaded design. It is important to note that a common nebulizer was not used with each of the different face masks during the testing, so it is unclear if these results were based solely on the mask or the nebulizer being used. Bottom-loaded face mask designs are believed to direct aerosol to the upper portion of the mask, whereas front-loaded masks direct aerosol toward the oronasal 
area. Moreover, the front-loaded mask design used in these studies (Bubbles the Fish II) has smaller entrainment ports on the sides of the mask and may provide a better seal compared with the other masks.

Recent advances in mask technology have introduced specialized masks that are placed over the nasal airway opening during an aerosol treatment. These delivery interfaces may be especially useful in infants because they are considered obligate nasal breathers. Based on data obtained from an in vitro study ${ }^{23}$ using anatomically accurate upper airway models of an infant and a young child, drug delivery was more efficient with a jet nebulizer using an aerosol face mask than with nasal masks. In the same study, drug delivery was similar between the nasal delivery systems and the aerosol mask in a newborn nasal airway model. The efficiency was very poor using nasal masks with the vibrating mesh nebulizer likely because a supplemental gas source was not used to move the aerosol plume through the mask dead space to the airway opening. Amirav et $\mathrm{al}^{40}$ used a specialized pacifier/nasal mask (SootherMask, InspiRx, Somerset, New Jersey) attached to a pMDI/VHC charged with radiolabeled isotopes in 10 infants. All of the sleeping infants readily accepted the transnasal mask treatment with little difficulty and had between $2.38 \%$ and $6.33 \%$ of the nominal dose delivered to the lungs. ${ }^{4}$

Treatments provided by a jet nebulizer attached to an infant hood may be less likely than a face mask to agitate infants and make them cry. Amirav et $\mathrm{al}^{41} \mathrm{com}-$ pared radiolabeled bronchodilator delivery between a jet nebulizer attached to an aerosol mask or a clear plastic infant hood in 14 wheezing infants. Drug delivery was similar, with mean lung drug depositions of $2.6 \%$ and $2.4 \%$ with the hood and mask, respectively. Another study ${ }^{42}$ assessed positional effects of drug delivery with a hood and found that the face-side position had less facial-ocular deposition than the face-up position while still achieving similar lung delivery efficiency. Moreover, treatment time and discomfort were shown to be lower in infants with chronic lung disease using the hood. ${ }^{43}$ In one study, ${ }^{44}$ respiratory scores were not different in infants with bronchiolitis receiving bronchodilators via an infant hood or a face mask, and parents preferred the hood over the mask for their babies. A hood represents a feasible option in children who will not tolerate a mouthpiece or mask treatment.

\section{Clinical Controversies}

\section{Drug Delivery in Crying Versus Resting Infants}

Effective delivery of aerosolized drugs and getting a patient to take a treatment are 2 of the most technically challenging aspects of pediatric respiratory care. Infants and small children may not tolerate a jet nebulizer attached to a face mask because it can be noisy, cold, and irritating, and the treatment time can be lengthy $(\sim 8-10 \mathrm{~min})$. Patients with acute lung disease are typically distressed and irritable. Placing a tight-fitting mask over the face may cause them to feel suffocated or scared, especially if this is their first time taking a treatment or the caregiver is unfamiliar to them. Although the face mask is a critical interface between the aerosolized drug and the small patient, it is often poorly tolerated, resulting in crying, screaming, tantrums, and, almost always, mask rejection. This can be extremely frustrating for everyone involved.

Previously, it was believed that screaming and crying resulted in effective drug delivery because the patient was able to take large $\mathrm{V}_{\mathrm{T}}$ and thus receive more of the drug into the lungs. Frustrated clinicians could often be observed holding the mask tightly to the screaming child's face for a long period of time. Although the clinician may feel that this is doing some good, it can create a very confusing and uncomfortable emotional environment for the clinician, family, and, most importantly, the patient. Infants who are distressed or crying have larger and more variable $\mathrm{V}_{\mathrm{T}}$, shorter inspiratory times, higher inspiratory flows, more prolonged expiratory times, and greater airway obstruction than at rest. ${ }^{45,46}$ These factors may result in aerosolized drug depositing on the face and upper airways or being swallowed and absorbed into the gastrointestinal tract. Several investigators have evaluated drug delivery in infants at rest and under emotional distress.

One study ${ }^{47}$ showed a nearly 4-fold increase in drug delivery in calm versus distressed infants with chronic lung disease. Erzinger et $\mathrm{al}^{10}$ delivered radiolabeled isotopes by nebulizer and $\mathrm{pMDI} / \mathrm{spacer}$ via a tight-fitting face mask in infants 18-36 months old. Lung deposition measured with scintigraphy was $0.6 \%$ and $1.4 \%$ with the pMDI/spacer and nebulizer, respectively, during screaming and $5.2-7.4 \%$ and $4.8-8.2 \%$ with the pMDI/spacer and nebulizer, respectively, during quiet restful breathing. The authors also showed that screaming resulted in a proportionally larger amount of drug deposition on the face and stomach, with substantially less in the lung than during quiet breathing (see Fig. 1). Results from a similar study ${ }^{11}$ showed drug deposition with a pMDI/VHC to be $<0.35 \%$ of the nominal dose in crying infants, which is nearly 5 -fold lower than when infants were calm or sleeping. Another study ${ }^{48}$ showed a nearly 5 -fold greater increase in drug deposition in sleeping infants than crying infants, and crying infants had more drug deposited in the central airways, whereas, sleeping infants tended to have better distribution into the distal airways.

Studies using bench models ${ }^{30}$ configured with previously recorded respiratory flows obtained from awake and sleeping infants showed that budesonide delivery with a $\mathrm{pMDI} / \mathrm{VHC}$ with mask was greater with the sleeping breath- 
Table 2. Infant Blow-By Studies With Jet Nebulizers and Different Airway Interfaces at Different Distances

\begin{tabular}{|c|c|c|c|c|c|c|c|}
\hline \multirow[b]{2}{*}{ Reference } & \multirow[b]{2}{*}{ Study Type } & \multirow[b]{2}{*}{ Interfaces Used } & \multirow[b]{2}{*}{ Airway Model } & \multicolumn{4}{|c|}{ Lung or Filter Deposition (\% Nominal Dose) } \\
\hline & & & & $\begin{array}{l}\text { Directly on } \\
\text { Face or Filter }\end{array}$ & $\begin{array}{l}<2 \mathrm{~cm} \text { From } \\
\text { Face or Filter }\end{array}$ & $\begin{array}{l}2 \mathrm{~cm} \text { From } \\
\text { Face or Filter }\end{array}$ & $\begin{array}{c}4 \mathrm{~cm} \text { From } \\
\text { Face or } \\
\text { Filter }\end{array}$ \\
\hline Everard et al ${ }^{51}$ & In vitro & $\begin{array}{l}\text { Facemask (bottom-loaded) } \\
\text { and T-piece }\end{array}$ & Rubber cone & $100^{*}$ & $40^{*}$ & $14^{*}$ & NA \\
\hline Restrepo et al ${ }^{52}$ & In vitro & $\begin{array}{l}\text { Facemask (bottom-loaded) } \\
\text { and T-piece }\end{array}$ & None (filter) & $\begin{array}{l}\text { Facemask: } 2.88 \\
\text { T-piece: } 4.14\end{array}$ & $\begin{array}{l}\text { Facemask: } 1.61 \\
\text { T-piece: } 3.77\end{array}$ & $\begin{array}{l}\text { Facemask: } 1.30 \\
\text { T-piece: } 3.45\end{array}$ & NA \\
\hline Erzinger et $\mathrm{al}^{10}$ & In vivo & Facemask & Human & NA & 0.3 & NA & NA \\
\hline Nikander et $\mathrm{al}^{39}$ & In vitro & Facemask (front-loaded) & Face (oral airway only) & $100 *$ & $105^{*}$ & $71^{*}$ & $26^{*}$ \\
\hline Lin et $\mathrm{al}^{34}$ & In vitro & $\begin{array}{l}\text { Facemask (bottom- and } \\
\text { front-loaded) }\end{array}$ & Face (oral airway only) & $2.18-3.67$ & $1.45-2.92$ & $0.92-2.26$ & NA \\
\hline $\begin{array}{l}\text { Mansour and } \\
\text { Smaldone }{ }^{38}\end{array}$ & In vitro & Facemask (3 types) & Face (oral airway only) & $1.14-5.33$ & $0.2-2.60$ & $0.14-1.48$ & $0.10-1.45$ \\
\hline $\begin{array}{l}\text { El Taoum } \\
\text { et } \mathrm{al}^{23}\end{array}$ & In vitro & $\begin{array}{l}\text { Facemask (front-loaded) } \\
\text { and T-piece }\end{array}$ & $\begin{array}{l}\text { Anatomically accurate } \\
\text { nasal/oral airway } \\
\text { model }\end{array}$ & Facemask: 1.52 & NA & $\begin{array}{l}\text { Facemask: } 0.73 \\
\text { T-piece: } 0.83\end{array}$ & NA \\
\hline
\end{tabular}

ing patterns than the awake breathing patterns $(6.5 \pm 3.2 \%$ vs $11.3 \pm 3.9 \%$, respectively). Nikander et al ${ }^{39}$ evaluated inhaled corticosteroid delivery via a pMDI/VHC and 2 small-volume nebulizers with masks in an anatomic replica of a 1-y-old child oral airway attached to a lung model that was configured for quiet breathing and crying. Crying reduced the inhaled drug mass from $1.3-4.6 \%$ to $<1 \%$ for the small-volume nebulizers, and that for the pMDI/spacer was $<1 \%$ for crying and quiet breathing. Based on these studies, it is preferable that a child is either sleeping or calm while providing a treatment. This can often be accomplished by waiting for the child to fall asleep or by having the parent hold the child and deliver the treatment so that patient can be soothed. However, studies ${ }^{4}$ in infants have shown that $70 \%$ of infants awaken during the placement of a mask treatment, and $75 \%$ of those become distressed or uncooperative. Nonetheless, efforts to minimize disturbances or wait until the patient is asleep may result in better drug deposition.

\section{Blow-By}

Blow-by aerosol therapy is accomplished using a gaspowered jet nebulizer placed within a reasonable distance from the patient, and the aerosol plume is directed toward the oral or nasal airway opening with an aerosol mask or T-piece with one end occluded. Anecdotal reports suggest that blow-by therapy is an attractive treatment option in infants who do tolerate a mouthpiece or mask treatment because it less likely to cause distress or crying. It is important to note that blow-by cannot be accomplished with a $\mathrm{pMDI} / \mathrm{VHC}$ or breath-actuated nebulizer because a poor mask seal results in lack of valve opening. Moreover, it cannot be used with a vibrating mesh nebulizer without supplemental gas flow. Proponents of blow-by claim that research supports use of blow-by via T-piece or corrugated tubing held half-an-inch $(1.27 \mathrm{~cm})$ or less from the face as a technique in those infants for whom a mask is not practical. ${ }^{49}$ Opponents of blow-by maintain that "blow-by is a waste of time, a waste of money, and an unnecessary irritation for the distressed child." 50 The American Association for Respiratory Care Clinical Practice Guideline for Aerosol Delivery Device Selection states that blow-by "is ineffective and should be discouraged." 17

There have been no published in vivo studies that have specifically addressed this highly controversial therapy. One in vivo study ${ }^{10}$ reported that drug delivery was negligible $(0.3 \%)$ in a calm infant receiving radiolabeled aerosols with a jet nebulizer and a large face mask leak (similar to blow-by). It has been speculated that the nebulizer device performance and interface design may play a large role in the effectiveness of blow-by drug delivery. The majority of research comparing these different systems has been in carefully designed bench tests, which are summarized in Table 2.

In a bench model study, Everard et al ${ }^{51}$ provided $20 \mathrm{mg}$ of $1 \%$ cromoglycate with a jet nebulizer and face mask (bottom-loaded) attached to a spontaneously breathing lung affixed with a rubber face cone model and at several distances from the airway opening. Moving the face mask away from the face model resulted in a $50 \%$ reduction in drug delivery at a distance of $1 \mathrm{~cm}$ and a $85 \%$ reduction at $2 \mathrm{~cm}$. Nikander et al ${ }^{39}$ measured the in vitro effects of blow-by in a spontaneously breathing infant oral airway 
model with a jet nebulizer and resuscitation mask held on the face model and at multiple distances. Interestingly, there was a 5\% increase in drug delivery when the mask was moved from the face model by $1 \mathrm{~cm}$. However, substantial reductions in drug delivery were observed when the nebulizer was moved away from the airway model, especially at distances $>3 \mathrm{~cm}$ (see Table 2). Mansour and Smaldone ${ }^{38}$ evaluated drug delivery at different distances using 3 different jet nebulizer/mask systems and the same infant oral airway model as used by Nikander et al. ${ }^{39}$ With the mask held tightly to the face, the inhaled mass for the PARI nebulizer system was greater compared with the other systems, and when these systems were held $4 \mathrm{~cm}$ from the face, the inhaled mass decreased by more than half, and facial and eye deposition on the model also varied depending on the system being used. Lin et al ${ }^{35}$ measured drug delivery using a lung model affixed to a spontaneously breathing infant oral airway model. A common nebulizer was used with 2 bottom-loaded masks and the Bubbles the Fish II mask at several distances. There were significant differences in inhaled mass at 0 and $2 \mathrm{~cm}$ (see Table 2), and the Bubbles the Fish II mask provided greater inhaled mass compared with the other masks at all 3 distances. Restrepo et al ${ }^{52}$ compared a blow-by technique using a bottom-loaded standard aerosol face mask and a T-piece with one port occluded with a jet nebulizer held at different distances from an oral airway face model and filter. The T-piece connector provided 2-fold greater drug mass than the face mask (1.3\% vs $3.45 \%)$ and greater fine-particle mass when the jet nebulizer was given blow-by at $2 \mathrm{~cm}$ from the inhalation filter.

These in vitro studies highlight not only the importance of a tight-fitting face mask, but also that, depending on the distance, blow-by may result in a 50-85\% lower dose than when the mask is held tightly to the face. These data also suggest that a T-piece or the Bubbles the Fish II mask (front-loaded mask) may facilitate a more direct stream of aerosol delivered to the airway compared with bottomloaded masks during blow-by. Although in vitro studies represent a suitable controlled environment to test differences in blow-by device performance, they do not take into account other important patient factors, such as patient head movement, respiratory pattern variability, airway humidification, and acceptance of the blow-by technique being used. It is important to note that these studies were limited by the use of simple airway model designs, many of which had large circular oral airway openings and a direct route for aerosol to deposit on the filters. ${ }^{35,36,37,52}$

As mentioned previously, infants and young children are obligate nasal breathers, and the upper airways represent a major area for drug particles to deposit, making therapeutic aerosol delivery to the lungs very difficult. El Taoum et $\mathrm{al}^{23}$ measured drug deposition during blow-by using anatomically accurate 3-dimensional neonatal and infant airway models attached to a breathing simulator with different interfaces. Regardless of the interface used, the vibrating mesh nebulizer provided no aerosol when the T-piece or aerosol mask was held $2 \mathrm{~cm}$ from the newborn and infant models. Drug delivery in the infant model was reduced by approximately half when the interface was moved from the face to a distance of $2 \mathrm{~cm}$, but there was no appreciable difference in drug delivery between the T-piece and face mask at $2 \mathrm{~cm}$ (see Table 2). Drug delivery in the neonatal model was similar between the different distances and interfaces used. These in vitro infant airway models ${ }^{23}$ showed a good correlation with in vivo data, ${ }^{10}$ but rendered lung doses severalfold lower than obtained in previous studies that used simplified oral airway models or filters.

Based on limited information from human data ${ }^{10}$ and one in vitro study that used realistic anatomic infant airways, ${ }^{23}$ it appears that regardless of the nebulizer or interface, blow-by provides negligible drug delivery to the lungs. As such, blow-by cannot be suggested as an alternative to a tight-fitting mask with a small-volume nebulizer or pMDI/VHC. An infant hood may be a better alternative for delivering inhaled medications to young children who cannot tolerate a face mask treatment.

\section{Jet Nebulizer Versus Pressurized Metered-Dose Inhaler/Spacer for Bronchodilators}

Inhaled bronchodilators are one of the most frequently prescribed medications for children admitted to the hospital with respiratory disorders. Historically, jet nebulizers have been the most common method of administration. Jet nebulizer treatments can be lengthy, noisy, cold on the face, and irritating. They are highly inefficient due to residual drug loss in the tubing and medication cup. Moreover, because drug is provided throughout the respiratory cycle, significant loss occurs on exhalation. Jet nebulizers also require a gas source or compressor, making them less portable and expensive to operate.

Common misconceptions about pMDI/spacers are that they are inefficient due to the large residual volume of drug remaining in the spacer chamber after pMDI actuation. Earlier spacer systems designed for adults had relatively large volumes, and infants were incapable of generating sufficient volumes to clear the chamber of drug. These aerosol devices are often perceived as being difficult to use because small patients are unable to coordinate inhalation with medication delivery, or the valves are not sensitive enough to open and provide drug to the patient.

Major advances in pediatric spacer technology have made it so that even small infants can use a pMDI for effective drug delivery. Small-volume spacers with well-fitting lowdead-space masks and low-resistance valves have overcome problems of coordination, and timing of pMDI ac- 
tuation to inhalation is less of a problem. Depending on patient size, infants can clear drug from a chamber in a fraction of the time it takes to take a jet nebulizer treatment ( $\sim 4$ to 5 breaths or $20-30$ s). A major advantage to the use of a $\mathrm{pMDI} / \mathrm{VHC}$ is that it is small and portable and does not rely on a gas source or electricity. Recent improvements in face mask and spacer technology have also provided VHCs that produce large quantities of fine-particle mass. Visual observation of a flap-valve indicator signals successful inhalation through the valve via the silicone face mask and confirms a good mask-to-face seal. Baffling systems are designed to trap large particles, thereby reducing oral impaction and minimizing systemic adverse effects. There are also audible indicators if inhalation force is excessive.

Most holding chambers are now produced from nonconducting or charge-dissipative materials (eg, polycarbonate or polyester) intended to minimize electrostatic charge, which may result in aerosol particles impacting on the sides of the chamber, thereby reducing the delivered dose. ${ }^{53,54}$ Chambers constructed with this material have been shown to provide greater pMDI drug delivery than those that are made from non-charge-dissipative material. ${ }^{55,56}$ Most children can master the technique of using a pMDI. Minai et $\mathrm{al}^{57}$ demonstrated that a systematic approach to teaching pMDI use to children resulted in sustained improvements in technique. Furthermore, pediatric subjects and families who had previously used small-volume nebulizers to administer bronchodilators overwhelmingly preferred pMDIs/VHCs after using them for a short time. 58

There have been a few studies in non-intubated infants and children that have evaluated drug delivery via jet nebulizers and pMDIs/spacers. Unfortunately, these studies compared jet nebulizers and pMDI using spacers that were not valved or constructed using charge-dissipative materials. Fok et al ${ }^{59}$ investigated radioaerosol deposition of salbutamol in 13 infants with bronchopulmonary dysplasia using a pMDI/VHC (non-charge-dissipative material) and a jet nebulizer with a mask. Lung deposition was highly variable. When lung deposition was expressed as a percentage of the initial nebulizer dose, 2 puffs of salbutamol via a pMDI/VHC provided greater drug than the jet nebulizer administering the same drug over $5 \mathrm{~min}$.

Tal et $\mathrm{al}^{11}$ evaluated bronchodilator delivery in 15 spontaneously breathing young children (mean age of 21 months, range of 3-60 months) with airway obstructions from asthma, cystic fibrosis, or bronchopulmonary dysplasia. They were administered one puff of radiolabeled technetium-99m via a pMDI with a $145-\mathrm{mL}$ holding chamber constructed of non-charge-dissipative material and a face mask. Mean aerosol deposition was $1.97 \%$ in the lungs, $1.28 \%$ in the oropharynx, and $1.11 \%$ in the stomach. The remainder of the drug was trapped in the spacer. In a spontaneously breathing young child model ( 2 y old) with an attached face model, we found that with a pediatricspecific small-volume VHC (AeroChamber Mini, Trudell Medical, London, Ontario, Canada) constructed from charge-dissipative material, bronchodilator drug delivery to a filter was $13.4 \%$ of the label claim. ${ }^{60}$

There is an emerging large body of clinical evidence that indicates that a pMDI/spacer is at least as effective as a small-volume nebulizer for bronchodilator delivery in infants and children. ${ }^{59,61-68} \mathrm{~A}$ recent Cochrane review $^{69}$ assessed outcomes from randomized trials regarding bronchodilator use with a $\mathrm{pMDI} / \mathrm{spacer}$ or a small-volume nebulizer in adults and children $(>2$ y old) with asthma. A total of 1,897 children and 729 adults in 39 trials were included. Thirty-three trials were conducted in the emergency room and equivalent community settings, and 6 trials were with in-patients with acute asthma (207 children and 28 adults). The method of bronchodilator delivery did not result in a significant difference in hospital admission rates, but stay in the emergency department was significantly shorter with the pMDI/spacer than with the jet nebulizer (103 vs $33 \mathrm{~min}$ ) in children. Lung function was also similar with the 2 delivery methods. Heart rate was lower with the spacer in children, as was the risk of developing tremors.

Historically, the major controversy between these 2 modalities has been related to the cost of therapy. Salyer et al ${ }^{70}$ conducted a hospital-wide conversion from jet nebulizers to pMDIs/VHCs for pediatric subjects ( $>2 \mathrm{y}$ old). $\mathrm{pMDI} / \mathrm{spacer}$ use increased from 25 to $77 \%$ in all nonintensive care patients receiving albuterol and from 10 to $79 \%$ in patients with asthma. Hospital stay was unchanged after conversion to pMDIs/VHCs for subjects with asthma. These investigators also realized a $21 \%$ reduction in total cost per treatment with pMDIs/VHCs compared with jet nebulizers and a 50\% reduction in labor costs. At the time of this publication, the price of a single albuterol pMDI canister was $\$ 2.45$. Following the federal ban of chlorofluorocarbon-based albuterol pMDIs, the comparative cost of albuterol hydrofluoroalkane pMDIs has nearly doubled or tripled at some institutions. This has caused many institutions to reconsider using small-volume nebulizers as a more cost-effective solution until a generic formulation for albuterol hydrofluoroalkane pMDIs is available.

\section{Continuous Nebulization}

Patients with status asthmaticus require high-dose bronchodilators to reverse airway obstruction from bronchoconstriction. Continuous nebulizers are typically provided with large-volume gas-powered jet nebulizers attached to a pediatric aerosol mask with aerosol tubing. Critically ill patients can also receive this form of therapy through a 
ventilator and some noninvasive devices. This approach is intended to provide uninterrupted high-dose bronchodilator delivery to patients who have not responded to therapy with a small-volume nebulizer or $\mathrm{pMDI} / \mathrm{spacer}$. A continuous nebulizer with $30 \mathrm{mg}$ delivered over $1 \mathrm{~h}$ is roughly equivalent to twelve $2.5-\mathrm{mg}$ nebulizers/h. Previous studies $^{71,72}$ reported that continuous inhaled bronchodilator administration is safe, effective, and less time-consuming than intermittent nebulization in patients with severe asthma.

Continuous nebulizers are most commonly used in emergency departments or pediatric ICUs. Regardless of patient location, continuous heart rate monitoring is preferred because high-dose bronchodilator delivery may result in tachycardia. One meta-analysis ${ }^{74}$ evaluated 8 trials and included a total of 461 subjects ( 229 subjects with continuous and 232 subjects with intermittent bronchodilator delivery), many of whom were children. Continuous bronchodilator administration was favored over small-volume nebulizers and resulted in fewer hospital admissions, greater improvements in peak flows, and greater percent-of-predicted $\mathrm{FEV}_{1}$ compared with jet nebulizers.

Only one study has evaluated outcomes in pediatric subjects with moderate-to-severe asthma receiving continuous bronchodilators. Kim et al ${ }^{73}$ evaluated clinical asthma scores in children supported by oxygen or a helium-oxygen mixture (heliox) during continuous nebulization. There were no differences in mean change in asthma scores from baseline to $240 \mathrm{~min}$, but emergency room discharge was 6.67 for the heliox group compared with 3.33 for the oxygen group. Eleven (73\%) subjects in the heliox group were discharged from the hospital in $<12 \mathrm{~h}$ compared with $5(33 \%)$ subjects in the group that received standard care with oxygen. There were no reported differences in adverse events between the 2 groups.

Continuous nebulization may be administered for several hours or even days. The treatment can be noisy and cold to the patient. Younger patients do not tolerate this treatment and typically reject the mask treatment. As such, patients must be continuously supervised to make sure that they are receiving drug. There is interest in using devices such as breath-actuated nebulizers and pMDIs/spacers as an alternative to continuous nebulization in patients with moderate-to-severe bronchoconstriction. Unlike continuous nebulizers, these devices provide pure drug only during inhalation, and because treatment times are shorter, they may be better tolerated. Levitt et $\mathrm{al}^{74}$ compared outcomes in subjects $>18$ y of age with acute bronchospasm who received bronchodilators via high-dose pMDIs/spacers and continuous nebulizers. They found that the $\mathrm{pMDI} / \mathrm{spacer}$ ( $\leq 24$ puffs depending on the peak-flow response) was equally effective as the continuous nebulizer $(15 \mathrm{mg} / \mathrm{h})$. Future studies evaluating similar outcomes with breath-actuated and continuous nebulizers in pediatric sub-

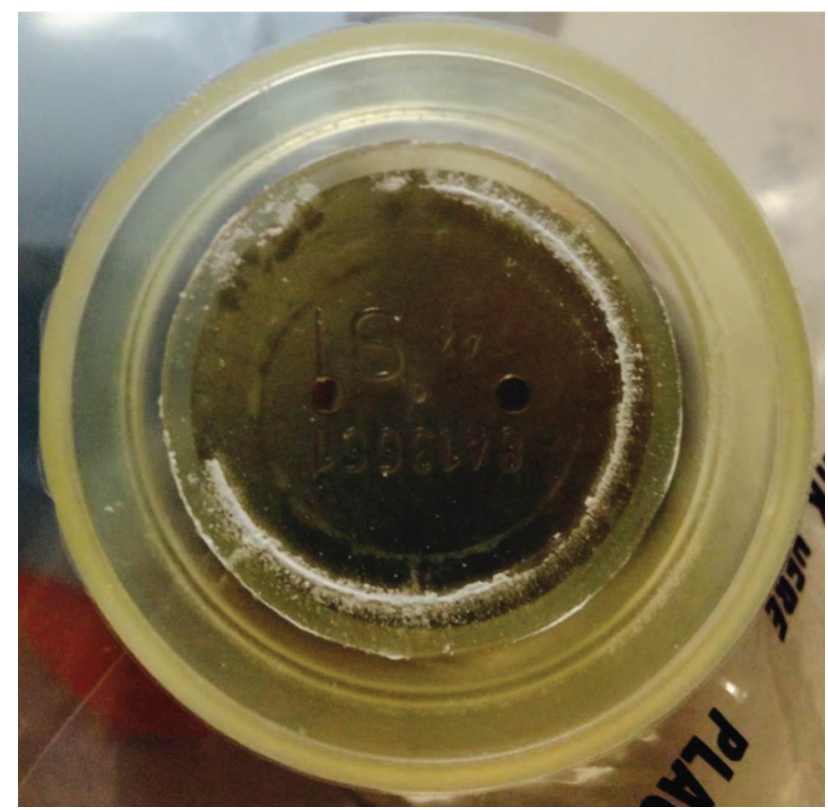

Fig. 2. Crystallization on the ventilator expiratory valve diaphragm due to continuous nebulization of albuterol. A double-filter system was being used on the expiratory circuit. The accumulated debris resulted in ventilator expiratory valve malfunction and circuit occlusion alarms.

jects are needed. These studies should also evaluate the cost and treatment duration of the 2 approaches.

Bronchodilators are frequently administered continuously during mechanical ventilation with a drip system using an intravenous pump, a syringe of albuterol (diluted with normal saline solution), and a vibrating mesh nebulizer. Most institutions will use a double-filter system to protect the ventilator expiratory valve from aerosol particles during nebulization. Filters can quickly become saturated with the albuterol/saline mixture, thus increasing expiratory resistance and placing patients at greater risk for developing high intrinsic PEEP (also known as autoPEEP). Even with filters placed in series, the expiratory valve systems may become corroded or gummed up with residue (Fig. 2), resulting in ventilator dysfunction and increased risk to the patient. Studies are under way to evaluate whether pure drug (no saline) may mitigate some of these risks. Clinicians may also consider high-dose $\mathrm{pMDI} / \mathrm{spacer}$ treatment in line or during manual ventilation as a potentially safer alternative to continuous nebulization.

\section{Noninvasive Respiratory Support}

There are several forms of pediatric noninvasive respiratory support used in the critical care setting to avoid intubation in patients or to facilitate weaning attempts following extubation. Historically, nebulizer therapy has not 
been administered using these devices in infants because there are few inhaled drugs that have been shown to be useful in this patient population. Many of these devices use a single-limb system with complicated gas-flow pathways and integrated leak valves. There are also several safety concerns related to triggering and volume delivery with these devices in infants, especially when using a jet nebulizer. As such, many infants and children are removed from noninvasive devices to provide inhaled medications. The advent of the vibrating mesh nebulizer and several novel inhaled medications (eg, aerosolized surfactant) has renewed interest in providing aerosolized drugs via heated and humidified high-flow nasal cannula (HFNC), nasal CPAP, and noninvasive positive-pressure devices (noninvasive ventilation [NIV] or bi-level positive airway pressure).

The use of HFNC has increased over the last decade in pediatric patients. It has been speculated that HFNC is better tolerated than nasal CPAP in infants due to the more comfortable nasal airway interface. Several anecdotal reports have suggested that young asthmatic patients may tolerate inhaled drug delivery better during HFNC than during face mask aerosol treatments. Multiple in vitro studies have evaluated drug delivery using different HFNC systems, flows, or gases..$^{75-78}$ Only one study ${ }^{77}$ used realistic pediatric anatomic airway models to compare drug delivery between an HFNC system and an aerosol face mask treatment. The authors noted substantially greater drug delivery using the aerosol mask compared with HFNC with a vibrating mesh nebulizer. This was not surprising considering that HFNC provided $98-100 \%$ relative humidity, and the face mask treatment used a dry gas (1.4$8.5 \%$ relative humidity). The flow-pathway resistance between these 2 devices and leak also play a vital role in drug loss. Little is known about the safety and efficacy of drug delivery using HFNC. There are concerns related to the condensate from drug and humidity accumulating in the cannula and becoming aspirated into the nasal airway opening (Fig. 3). Anecdotal reports have also shown significant skin irritation from impacted bronchodilators running down the nose and face during this combined therapy.

Initial attempts to integrate jet nebulizers into nasal CPAP flow generators (Infant Flow CPAP, CareFusion, San Diego, California) were described by Smedsaas-Löfvenberg et al ${ }^{79}$ when they modified flow channels within a fluidicflip pressure generator attached to short bi-nasal prongs to provide epinephrine, salbutamol, budesonide, acetylcysteine, natural surfactant, and ribavirin to sick infants. This approach never resulted in an actual product, and it is unclear if the flow from the jet nebulizer affected CPAP levels in infants.

More recent studies have addressed bronchodilator delivery in CPAP systems using a vibrating mesh nebulizer. Sunbul et al ${ }^{80}$ compared bronchodilator drug delivery us-

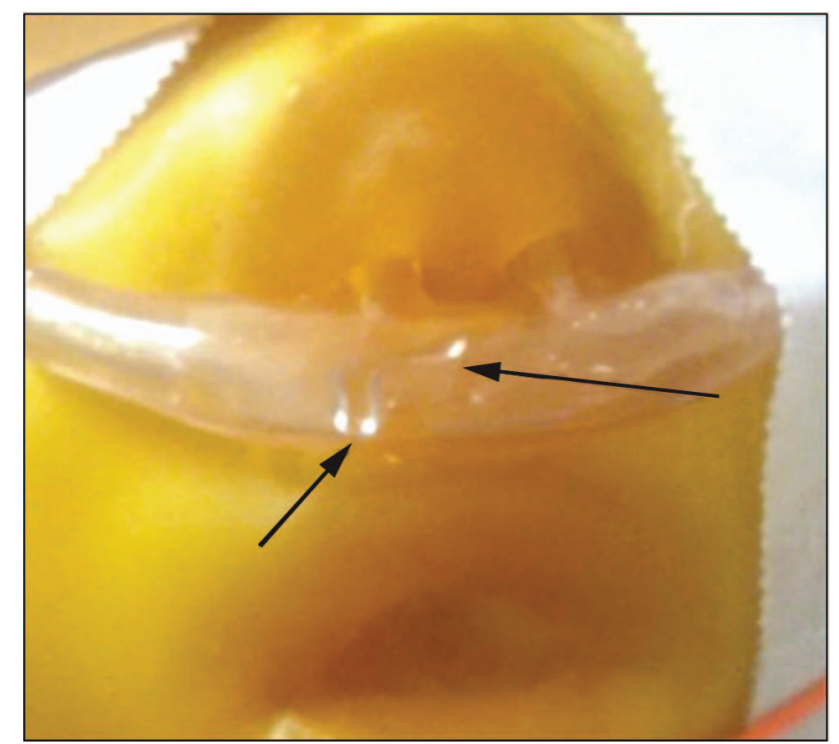

Fig. 3. Fluid accumulation within the walls of a heated high-flow nasal cannula (arrows) in an anatomic airway model during vibrating mesh nebulization. Fluid was jetting from the cannula into the nasal airway opening and then leaking out onto the face model.

ing a vibrating mesh nebulizer placed proximal to the patient interface and on the dry side inlet of the humidifier via HFNC, sigh intermittent mandatory ventilation (SiPAP), and bubble CPAP. They used a spontaneously breathing lung model affixed with a realistic low-birthweight anatomic nasal airway cast. All devices were adjusted to obtain similar baseline pressures using proprietary nasal airway interfaces. Medication delivery to the lung model filter was quite low $(<1.5 \%)$ with all testing conditions. Overall, SiPAP provided lower drug mass compared with HFNC and bubble CPAP, likely due to drug loss in the nasal pressure generator. There were also no differences between the nebulizer circuit positions for HFNC and SiPAP, but during bubble CPAP, nebulizer placement at the humidifier provided greater drug delivery than when placed proximal to the subject.

Farney et al ${ }^{81}$ showed greater delivery of technetium99m-labeled diethylenetriaminepentaacetic acid via a vibrating mesh nebulizer placed $32 \mathrm{~cm}$ from nasal CPAP prongs then when placed before the humidifier (21\% vs $0.3 \%$ ) during simulated neonatal CPAP (Infant Flow SiPAP [CPAP setting], CareFusion). Residual impactive aerosol losses were characterized within the delivery pathways between the different nebulizer locations. The resulting losses when the nebulizer was placed before the humidifier and proximal to the nasal prongs occurred in the nebulizer cup $(10 \pm 4 \%$ vs $33 \pm 13 \%)$, exhalation limb $(9 \pm 17 \%$ vs $26 \pm 30 \%)$, and generator tubing $(21 \pm 11 \%$ vs $19 \pm 20 \%$ ). Placing the nebulizer close to the humidifier resulted in $59 \pm 8 \%$ of the aerosol being deposited in the 
inhalation tubing along the heater wire and $<0.5 \%$ to the lung model.

It would be difficult to compare the findings and make assumptions based on nebulizer position in the patient circuit in the studies by Farney et $\mathrm{al}^{81}$ and Sunbul et $\mathrm{al}^{80}$ because CPAP was provided with different devices and settings. Moreover, Sunbul et al ${ }^{80}$ used a realistic anatomic airway cast, and Farney et $\mathrm{al}^{81}$ did not. It appears that nebulizer efficiency is similar between the 2 positions during HFNC: greater during single-circuit variable-flow CPAP when placed proximal to the patient and greater when placed before the humidifier in the dual-limb circuit with constant-flow bubble CPAP.

NIV or bi-level positive airway pressure devices used in children outside of the neonatal setting incorporate a single-limb patient circuit with an integrated leak port exhalation valve to purge the circuit of exhaled carbon dioxide. Studies using adult lung models ${ }^{82,83}$ have shown that placing the jet nebulizer after the leak and as close to the patient mask as possible results in the greatest drug delivery. However, until very recently, many of the pediatric oronasal mask interfaces were prepackaged with the leak exhalation port integrated into the mask, making it physically impossible to place a nebulizer between the leak and the mask. Also, the weight and awkwardness of placing available aerosol delivery devices in series close to the patient may add tension to the mask, resulting in greater leakage and lower drug delivery to the patient. Because of these factors and the fact that triggering may be affected by a jet nebulizer, many clinicians have not provided this controversial therapy.

The lightweight NIVO vibrating mesh nebulizer (Philips Respironics, Murrysville, Pennsylvania) represents a suitable new noninvasive nebulizer technology that obviates many of the previous concerns related to pediatric drug delivery during NIV. One study ${ }^{84}$ showed greater albuterol mass delivered to a spontaneously breathing pediatric airway/lung model with the NIVO nebulizer integrated into the mask compared with the Aeroneb Solo vibrating mesh nebulizer (Aerogen, Mountain View, California) placed at multiple locations in the circuit. When the vibrating mesh nebulizer was placed before the exhalation leak valve, greater drug delivery was observed when the nebulizer was placed closer to the leak valve than when placed before the humidifier. Based on these findings, it seems that clinicians should avoid placing the nebulizer before the humidifier to avoid aerosol impaction within the circuit. If the NIVO vibrating mesh nebulizer is unavailable, a vibrating mesh nebulizer should be placed as close to the patient as possible and after the exhalation leak valve. Also, children using nebulizers with nasal masks may have large oral leaks that may result in less drug delivery. Chin straps may help provide a better oral seal and alleviate some of these issues.

\section{Optimizing Nebulizer Performance During Mechanical Ventilation}

Inhaled bronchodilators still remain the most widely used inhaled drugs in mechanically ventilated patients. They are routinely administered to toddlers and older children. Inhaled bronchodilator therapy in preterm and term infants may improve compliance and $\mathrm{V}_{\mathrm{T}}$ and decrease pulmonary resistance, especially in infants with chronic lung disease ${ }^{85-87}$ Figure 4 shows ventilator airway graphics before and following 4 puffs of a bronchodilator in a 25week former preterm infant with bronchopulmonary dysplasia.

Over the last decade, several inhaled prostacyclins (prostaglandin I2) have been administered to infants with persistent pulmonary hypertension during mechanical ventilation. ${ }^{88-90}$ Improvements in nebulizer performance and artificial lung surfactant formulations have provided improved outcomes in mechanically ventilated preterm animal models and are likely to be used more frequently in the clinical setting in the coming years. ${ }^{91}$ Inhaled hypertonic saline, as well as corticosteroids and mucolytics, are also administered through the ventilator circuit at some pediatric institutions.

Experimental data obtained from in vivo studies have demonstrated poor aerosol delivery to ventilated patients, with $\sim 1 \%$ of the nominal dose being delivered to the peripheral airways of infants. ${ }^{16}$ Data on older pediatric patients are lacking. There are several practical issues complicating the efficacy of drug delivery during mechanical ventilation, including the patient's lung mechanics, ventilator brand, ventilation mode, aerosol generator, heating and humidification of the inspired gas, position of the aerosol generator in the ventilator circuit, timing during the respiratory cycle, endotracheal tube (ETT) size, $\mathrm{V}_{\mathrm{T}}$, inspiratory flow, and bias-flow setting. ${ }^{92}$

There is no consensus for choosing a nebulizer device, and practices vary widely from one institution to the next. A survey from 1996 showed that $85 \%$ of neonatal ICUs never used a pMDI for bronchodilator administration and relied more on jet nebulizers (unpublished data). ${ }^{63} \mathrm{~A}$ survey from 2002 showed that $57 \%$ of neonatal ICUs used pMDIs/spacers, and $31 \%$ of the centers surveyed provided spacers in-line with the ventilator, and 56\% removed the patient and provided a pMDI with a spacer using a manual resuscitator. ${ }^{63} \mathrm{~A}$ survey of large pediatric patients has never been conducted, but it is likely that there are large variations in practice.

There are concerns about clinical deterioration when removing patients from the ventilator for inhaled drug administration. Frequent breaks in the circuit may increase the risk for colonization and consequent ventilator-acquired pulmonary infections. Manual resuscitation is frequently associated with excessive $V_{T}$ and iatrogenic lung injury. ${ }^{94}$ 

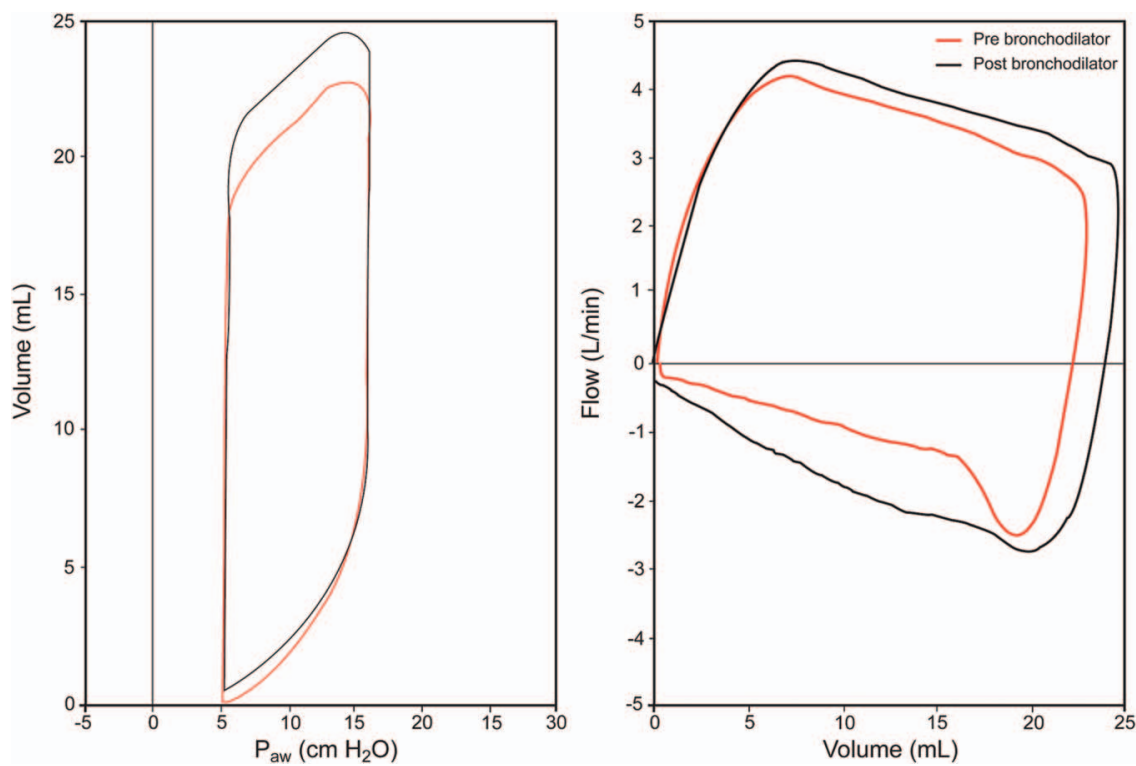

Fig. 4. Pressure-volume and flow-volume loops during mechanical ventilation in a 25 -week former preterm infant with chronic lung disease before (black line) and after (red line) bronchodilator therapy. Reductions in airway resistance resulted in changes in tidal volume and curvature in the expiratory flow-volume loop. $\mathrm{P}_{\mathrm{aw}}=$ airway pressure.

Collapsible in-line spacers placed into the inspiratory limb of a ventilator can be used for pMDI administration to reduce the risk of interrupting the circuit. Short-term delivery has been shown to be efficient with in-line spacers; however, once visible condensate occurs, drug delivery efficiency can be decreased by $\sim 50 \% .{ }^{95}$

There has been some speculation that children with severe airway obstruction may benefit from being removed from the ventilator so that emergent treatments provided with a manual resuscitator can be given. Grigg et al ${ }^{96}$ found that 3 puffs of cromoglycate via a $\mathrm{pMDI} /$ spacer and manual resuscitation and $20 \mathrm{mg}$ delivered to ventilated infants via a ultrasonic nebulizer during mechanical ventilation resulted in lung delivery of $1.7 \%$ and $1.3 \%$, respectively. However, the spacer used was not valved or constructed using charge-dissipative materials. In one in vitro study, ${ }^{60}$ bronchodilator delivery with a pMDI/pediatric-specific VHC constructed of charge-dissipative material was $4.2 \%$ and $11.9 \%$ during mechanical and manual ventilation, respectively, in a newborn lung model and $4.7 \%$ and $11.1 \%$, respectively, in a 2 -y-old child model. $\mathrm{V}_{\mathrm{T}}$ and breathing frequencies were similar during testing, but the major increase in drug delivery observed during manual ventilation was thought to be related to the fact that a humidifier was not used. Previous studies have shown that medication delivery administered within a humidified ventilator circuit $(100 \%$ body temperature and pressure saturated) can be reduced by as much as $40 \%$ compared with that administered within a non-humidified circuit under room ambient conditions. ${ }^{97,98}$ Clinical conditions that warrant timely and efficient drug administration of bron- chodilators (ie, status asthmaticus) may respond well to a pMDI/VHC with manual ventilation due to the lack of humidity, but this would need to be studied using in vivo models. These findings also raise the question, for an ongoing clinical debate, about whether active humidifiers should be turned off intermittently or bypassed while aerosolized drugs are being administered through the ventilator system. Although this practice cannot be routinely recommended at this time, it encourages additional research. New devices that circumvent the issues of drug loss related to the humidified environment during mechanical ventilation are under development. ${ }^{99}$ Finally, children who require chronic ventilation at home and do not tolerate jet nebulizers placed in line commonly receive pMDI/VHC treatments with a manual resuscitator.

There has been only one in vivo study that has evaluated differences in drug delivery between a pMDI/spacer and a jet nebulizer in mechanically ventilated children. Fok et al ${ }^{59}$ evaluated scintigraphy of aerosol deposition in 1-4-kg ventilated neonates with a jet nebulizer, reporting deposition ranging from 0.2 to $0.6 \%$ of the nominal dose. Lung deposition with the $\mathrm{pMDI} / \mathrm{spacer}$ was greater compared with the nebulizer $(0.98 \pm 0.19 \%$ vs $0.22 \pm 0.08 \%)$. There was huge inter-subject variability in lung deposition. Studies in mechanically ventilated small animals ${ }^{100-102}$ have also shown that jet nebulization is highly inefficient $(<1 \%)$ during infant conventional ventilation. Another study 88 found that $20 \mathrm{mg}$ delivered to ventilated infants via an ultrasonic nebulizer during mechanical ventilation resulted in $1.3 \%$ of the emitted dose. In another animal study, Fok 
et al ${ }^{101}$ showed nearly 2 -fold greater drug delivery with an ultrasonic nebulizer than a jet nebulizer.

There has been one in vivo study comparing jet and vibrating mesh nebulizers in aerosol delivery during infant ventilation. Dubus et al ${ }^{103}$ ventilated 4 intubated macaques $(2.6 \mathrm{~kg}$ ) and nebulized $3 \mathrm{~mL}$ containing radiolabeled aerosol with a AirLife Misty-Neb jet nebulizer (Allegiance Healthcare Corporation, McGaw Park, Illinois) and 0.5 $\mathrm{mL}$ with an Aeroneb Pro (Aerogen) placed in the inspiratory limb and $10 \mathrm{~cm}$ from the patient Y-piece. Deposition was $12.6 \%$ (range of 9.6-20.6\%) with the vibrating mesh nebulizer and $0.5 \%$ (range of $0.4-1.3 \%$ ) with the jet nebulizer. It is important to note that no humidification was used in the ventilator circuit, and these data should be approached with some trepidation.

In one in vitro study ${ }^{104}$ evaluating drug delivery with current-generation microprocessor-controlled ventilators, vibrating mesh nebulizers were shown to be highly efficient, providing 2-4 times greater drug delivery than jet nebulizers during pediatric mechanical ventilation. They also allowed medication to be delivered without having to disconnect the patient from positive pressure and could remain in line when not being used. Unlike jet nebulizers, no flow was added to the patient circuit by the vibrating mesh nebulizers. The addition of supplemental inspired gas directly into the ventilator circuit can alter $\mathrm{V}_{\mathrm{T}}$ delivery or measurement by some ventilators. ${ }^{105}$ Avoiding the addition of extra flow into the circuit may prevent patientventilator asynchrony from ineffective triggering that often occurs in pediatric patients.

Currently, one of the largest ongoing clinical controversies surrounding inhaled medication delivery during pediatric ventilation is where to place the nebulizer in the ventilator to minimize hygroscopic growth of aerosols and reduce impaction within the inspiratory limb of the patient circuit. Moreover, because most aerosol generators produce particles throughout the respiratory cycle, bias flow from the ventilator carries drug to the exhalation limb during exhalation, resulting in potentially less drug delivered to the lungs. As such, definitive data are lacking to suggest that all aerosol-generating devices, using the array of available ventilators, are safe and effective or whether different nebulizer locations could provide similar results in infant, pediatric, and adult patients.

Ari et $\mathrm{al}^{106}$ evaluated jet, vibrating mesh, and ultrasonic nebulizer efficiency with a bronchodilator at 3 locations during simulated adult ventilation (comparable to an adolescent). With the exception of the jet nebulizer, medication delivery was most efficient when the vibrating mesh and ultrasonic nebulizers were positioned 6 inches from the patient Y-piece. Under most testing conditions, the jet nebulizer delivered less aerosolized medication to the lung model compared with the other devices. Because the jet nebulizer is the only aerosol generator that uses an exter- nal pressurized continuous gas source, it is likely that a significant proportion of the aerosolized particles leave the patient circuit during exhalation, resulting in less available medication for delivery during the inspiratory phase, especially when the nebulizer is placed proximal to the patient Y-piece. There was a tendency for the jet nebulizer to become more efficient when positioned farther away from the patient Y-piece and closer to the ventilator (before the humidifier). An opposite effect was observed when using the other 3 devices, which do not add flow to the system during nebulization. The authors discussed the possibility that the inspiratory limb becomes charged with aerosol particles with a jet nebulizer during the expiratory phase, acting as an aerosol reservoir, which likely results in greater medication delivery during inhalation. In this particular study, the authors chose to disable the flow trigger and hence bias flow. It is quite possible that the vibrating mesh and ultrasonic nebulizers would have been more efficient when placed before the humidifier if bias flow was present to facilitate movement of the drug bolus down the ventilator circuit.

Ari et $\mathrm{al}^{104}$ confirmed this finding when they designed a study to address the effects of bias flow and medication delivery using jet and vibrating mesh nebulizers at 2 positions in a humidified circuit during simulated adult and pediatric mechanical ventilation. The vibrating mesh nebulizer provided nearly 2 -fold greater drug delivery than the jet nebulizer. The placement of the jet nebulizer in this study was similar in location to 2 of the positions in a study that used an adult test lung model. ${ }^{106}$ The most intriguing finding from these 2 studies was the nearly 3 -fold increase in medication delivery that was observed using a vibrating mesh nebulizer with bias flow of $2 \mathrm{~L} / \mathrm{min}$ versus no bias flow. Based on these data, it appears reasonable to assume that the delivery of medication is augmented by bias flow when the vibrating mesh nebulizer is placed at the ventilator, similar to how the efficiency of the jet nebulizer increased the farther it was moved away from the patient Y-piece. ${ }^{106}$ The authors mentioned that in most cases, the aerosol bolus formed by the vibrating mesh nebulizer remained in the vicinity of the aerosol generator when bias flow was not used. Therefore, it appears that the movement of the bolus is facilitated farther into the inspiratory limb of the ventilator with bias flow during exhalation to produce a ventilator breath that is possibly charged with more aerosolized particles. Although this reservoir-like effect is the most likely reason for explaining the large increases in drug delivery with a vibrating mesh nebulizer placed proximal to the humidifier, these effects are likely minimized in ventilators that incorporate bias flow for triggering or that have low bias flows.

Berlinski and Willis ${ }^{107}$ compared bronchodilator drug delivery at multiple locations via a vibrating mesh nebulizer, an ultrasonic nebulizer, and 2 different jet nebulizers 
during simulated pediatric ventilation. They found that the vibrating mesh nebulizer was also superior to the 2 other jet nebulizers under all tested conditions and to the ultrasonic nebulizer when placed at either the humidifier or ventilator. The authors also showed significantly greater drug delivery when the vibrating mesh nebulizer was placed between the ventilator and humidifier compared with on the inspiratory limb and proximal to the patient airway during simulated pediatric ventilation. It is worth noting that they used a larger circuit, larger $\mathrm{V}_{\mathrm{T}}$, and longer exhalation time compared with Ari et al. ${ }^{104}$ This may also help explain why they observed 2-fold greater amounts of drug delivered to the filter with a vibrating mesh nebulizer than did Ari et al. ${ }^{104}$

Optimizing drug delivery during neonatal ventilation becomes further complicated due to the use of small circuits, ETTs, short inspiratory times, and low $\mathrm{V}_{\mathrm{T}}$. Our laboratory evaluated inhaled iloprost drug delivery with a vibrating mesh nebulizer placed proximal to the patient Y-piece and between the ventilator and humidifier during simulated neonatal ventilation. ${ }^{108}$ Low $\mathrm{V}_{\mathrm{T}}(24 \mathrm{~mL})$, rapid breathing frequencies ( 60 breaths/min), and humidification were used with the ventilator attached to a realistic neonatal test lung. Drug delivery was greater with the nebulizer placed proximal to the airway than back on the dry side of the humidifier (10.74\% vs $2.96 \%$ ). This is the first neonatal aerosol study to ever report double-digit drug delivery during mechanical ventilation with an ETT.

A similar study by Parker et al ${ }^{109}$ evaluated a vibrating mesh nebulizer with inhaled treprostinil (United Therapeutics, Denver, Colorado) at 2 circuit locations (before the humidifier and before the patient Y-piece) during simulated neonatal, pediatric, and adult mechanical ventilation. Greater drug delivery was observed with the nebulizer placed before the humidifier during adult ventilation, but there were no significant differences between the 2 positions during neonatal and pediatric ventilation. Of note, the ventilator used in this study provided a bias flow of $0.5 \mathrm{~L} / \mathrm{min}$ during neonatal ventilation and $1.5 \mathrm{~L} / \mathrm{min}$ during pediatric and adult ventilation, and the other study 108 used a ventilator that provided a bias flow of $2 \mathrm{~L} / \mathrm{min}$. These conflicting infant testing data support the hypothesis that higher bias flows $(\sim 2 \mathrm{~L} / \mathrm{min})$ may result in greater impactive drug loss and shorter dwell times in the inspiratory circuit than neonatal ventilators that use low bias flows $(\sim 0.5 \mathrm{~L} / \mathrm{min})$. Table 3 provides a potentially useful compendium of data to guide clinicians when using the array of small-volume nebulizers with varying bias flows and nebulizer circuit locations.

Assuming similar bias flows and ventilator designs, the best explanation for differences in drug delivery between neonates and larger simulated pediatric and adult patient models is the proportionately smaller volumes, shorter inspiratory times, and faster rates. Assuming that a ventilator uses a bias flow of $2 \mathrm{~L} / \mathrm{min}$, this equates to $33 \mathrm{~mL} / \mathrm{s}$ moving through the circuit during exhalation. For a large pediatric (adult) circuit, at a rate of 15 breaths/min with a 1 -s inspiratory time, the $3 \mathrm{~s}$ between inspirations can move part of the aerosol bolus $(100 \mathrm{~mL})$ down the circuit and into the expiratory limb, reducing the inhaled dose. Assuming a $10-\mathrm{mm}$ inner diameter infant circuit with a $180-\mathrm{mL}$ inspiratory circuit volume, a $\mathrm{V}_{\mathrm{T}}$ of $20 \mathrm{~mL}$ requires $\sim 9$ breaths to move a bolus of aerosol from the ventilator to the patient airway when the nebulizer is placed before the humidifier. With a bias flow of $2 \mathrm{~L} / \mathrm{min}$, the drug bolus will move from the ventilator position through the $10-\mathrm{mm}$ circuit at $33.3 \mathrm{~mL} / \mathrm{s}$. With a $\mathrm{V}_{\mathrm{T}}$ of $20 \mathrm{~mL}$, the aerosol bolus moves $53.3 \mathrm{~mL}$ with each breath, taking 4 breaths (and $3.3 \mathrm{~s}$ ) for aerosol to travel from the nebulizer to the patient airway. The transition from baseline to peak inspiratory flow creates turbulence and results in impactive losses, whereas the 3.3-s residence time of aerosol in the $10-\mathrm{mm}$ inner diameter circuit leads to losses from gravitational sedimentation. Placing the nebulizer in the inspiratory limb proximal to the airway during neonatal ventilation may result in some movement of drug toward the exhalation limb during exhalation, but overall, the aerosol spends less time in the inspiratory limb of the circuit, and a greater proportion of the aerosol bolus is thus delivered to the airway.

Based on previous studies and clinical experience, it appears that the vibrating mesh nebulizer represents a potentially safer and more efficient drug delivery system than the jet nebulizer during pediatric ventilation. However, the cost of this drug delivery system may not be feasible for many institutions. There are so many variables affecting drug delivery during mechanical ventilation that it is impossible to suggest a single nebulizer or circuit location with the array of different nebulizers, drugs, ventilators, and patient sizes. Standard jet nebulizers should be avoided during infant ventilation due to poor triggering, inaccurate volume monitoring, and concerns related to volume and pressure delivery to the lungs. Some jet nebulizers can be operated at low flows ( $\sim 2 \mathrm{~L} / \mathrm{min})$. It is unclear how these devices impact triggering and other safety outcomes. In most cases, it may be challenging to place a nebulizer in series between the ETT and patient Y-piece due to dead space and unnecessary torque on the airway during pediatric ventilation. Based on recent data, the vibrating mesh nebulizer should be placed in the inspiratory limb and proximal to the patient Y-piece and not before the humidifier to optimize drug delivery during neonatal ventilation. Future studies are needed to determine the exact volume, inspiratory time/rate setting combination, circuit size, and bias flow that result in differences in medication delivery between the different locations. Moreover, new research must focus on drug delivery and neb- 


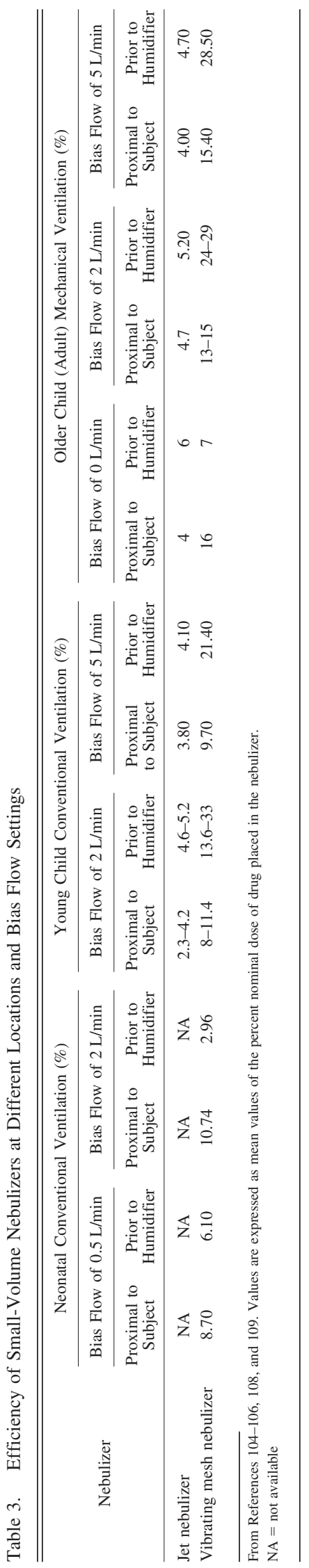

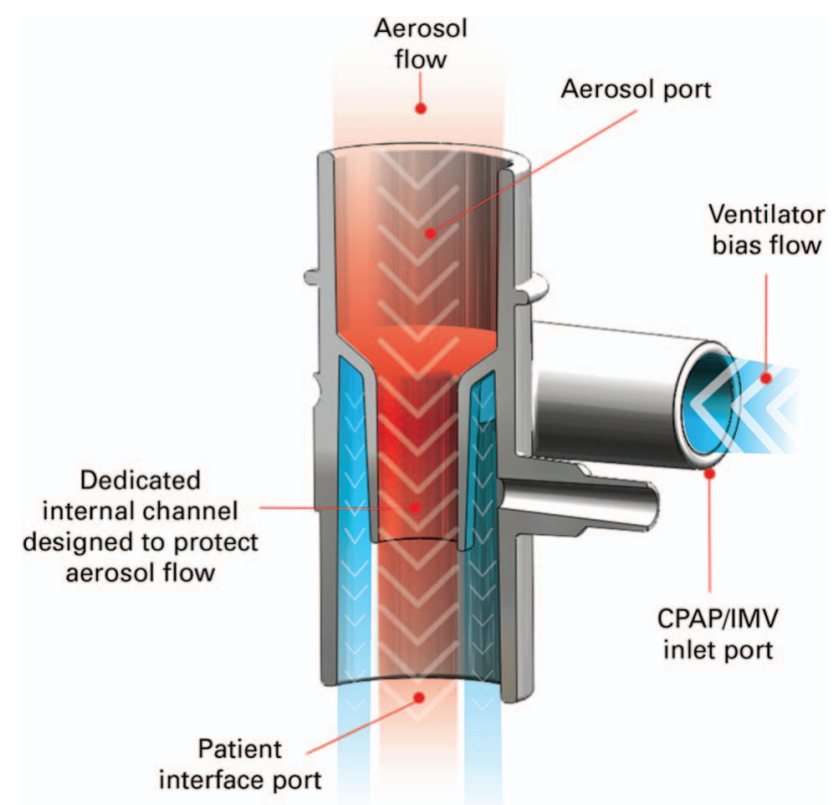

Fig. 5. A novel multi-channeled neonatal patient $Y$-piece device (AFECTAIR) developed as part of an aerosolized lung surfactant administration system to be used with AEROSURF (lucinactant), a form of inhaled lung surfactant. The AFECTAIR uses fluidic principles to effectively decouple ventilator bias flow from nebulizer flow pathways and provide a more direct route into the airway. Not only does this provide less drug delivered into the expiratory circuit, but by providing a more direct route and hence laminar flow to the airway, less drug impaction may occur in the artificial airways. IMV = intermittent mandatory ventilation. Courtesy Discovery Labs.

ulizer performance with existing and new iterations of mechanical ventilator platforms.

Recently, a novel multi-channel neonatal patient Y-piece device (AFECTAIR, Discovery Labs, Warrington, Pennsylvania) (Fig. 5) was developed as part of an aerosolized lung surfactant administration system to be used with AEROSURF (lucinactant), a form of inhaled lung surfactant. The AFECTAIR design uses fluidic principles to effectively decouple ventilator bias flow from nebulizer flow pathways and provide a more direct route into the airway. Not only does this result in less drug being delivered into the expiratory circuit, but by providing a more direct route and hence laminar flow to the airway, less drug impaction may occur in the artificial airways. This can be used only with a nebulizer that provides supplemental flow. It is unclear if the separate pathways may mitigate the effects of poor trigger response and drug accumulation on a neonatal proximal-flow sensor. This device is approved for use of an aerosol surfactant delivery system. Mazela et al ${ }^{110}$ evaluated bronchodilator aerosol delivery with an AirLife Misty Finity jet nebulizer (Cardinal Health, Dublin, Ohio) at $2 \mathrm{~L} / \mathrm{min}$ delivered through the AFECTAIR and at $20 \mathrm{~cm}$ from the patient Y-piece during simulated neonatal venti- 
lation. They observed greater nebulizer efficiency with the AFECTAIR adapter than when the nebulizer was placed into the ventilator circuit at the different ventilator settings (1.8-11.3\% vs $0.1-1.2 \%$, respectively).

Many infant and some adult ventilators require proximal-flow sensors to be placed at the airway during normal operation. Medication condensate from a nebulizer treatment can accumulate within these sensitive flow sensors, affecting patient triggering, quality of airway graphics, $\mathrm{V}_{\mathrm{T}}$ accuracy, and ventilator operation. Also, the effectiveness of a treatment may be compromised in patients when the nebulizer is placed in series with a flow sensor. High resistance, dead space, and variable temperatures may result in virtually no drug delivery to the patient. This may be dependent on the type of flow sensor being used (ie, hot wire vs fixed orifice). As such, the proximal-flow sensor is typically removed for a short-term nebulizer treatment, or patients are moved to a larger pediatric or adult setting on the ventilator. This may impact patient triggering and volume measurements as well as other safety issues in patients, especially if they are receiving continuous nebulizer treatments or a drug that has a tendency to produce sticky residue.

Inhaled drug delivery during pediatric high-frequency ventilation has been highly controversial. Many clinicians forego its use because it is unclear if any drug makes it to the lungs due to extremely short inspiratory times, high bias flows, and extremely low $\mathrm{V}_{\mathrm{T}}$. Using a pMDI with a holding chamber placed at the airway, Garner et al ${ }^{111}$ reported negligible delivery of albuterol to a filter placed distal to the ETT. Sood et al ${ }^{112}$ evaluated drug delivery efficiency using a low-flow jet nebulizer with prostaglandin E1 during neonatal conventional and high-frequency ventilation. They reported $32-40 \%$ of the nominal dose and only $0.1 \%$ during conventional and high-frequency ventilation, respectively. Their model had a major limitation in that they collected the drug as condensate at the end of the ETT deposited in a closed bottle. In contrast, in our study, ${ }^{108}$ the vibrating mesh nebulizer placed at the airway delivered only one third of the drug reported by Sood et al, ${ }^{112}$ but 3 -fold more drug was observed with highfrequency oscillatory ventilation (HFOV) than with continuous mandatory ventilation. Sood et al ${ }^{113}$ also compared aerosol delivery using a low-flow jet nebulizer during conventional, high-frequency, and high-frequency jet ventilation in an infant test lung model. In this model, the distal tip of the ETT was placed in a sponge open to the atmosphere. The authors reported greater deposition with conventional ventilation than with high-frequency jet ventilation and HFOV.

Our laboratory reported greater drug delivery with the nebulizer placed proximal to the patient compared with at the humidifier during simulated neonatal conventional and high-frequency ventilation. ${ }^{108}$ There was a nearly 3 -fold greater increase in drug delivery during HFOV compared with conventional ventilation at the proximal location ( $29.74 \%$ vs $10.74 \%)$. We conducted a similar study ${ }^{109}$ that quantified inhaled treprostinil delivery using a vibrating mesh nebulizer during simulated infant, small pediatric, and adult (also known as large child) ventilation with both conventional and high-frequency ventilators. There was nearly 2-fold greater drug delivery with HFOV compared with conventional ventilation in the infant and small pediatric lung model filters, but this relationship was opposite in the adult model.

During HFOV, the placement of the aerosol generator at the humidifier may dilute the aerosol with the high bias flow $(20 \mathrm{~L} / \mathrm{min})$ and reduce aerosol delivery due to impaction within the expiratory limb. The complex gas-flow mechanisms that govern HFOV may be a likely explanation for the double-digit recovery observed in this study. ${ }^{108}$ The combination of much shorter inspiratory times, higher frequencies, and active exhalation during this form of ventilation may make it less likely for the drug to be delivered to the expiratory limb, resulting in greater delivery to the lung than during conventional ventilation. Moreover, the only place to integrate a nebulizer during HFOV is between the ETT and patient Y-piece. This placement likely increases mechanical dead space, but drug delivery may be optimized because the aerosol plume is relatively unaffected by bias flow.

\section{Conclusions}

Pediatric patients have differences in airway anatomy, breathing frequencies, $\mathrm{V}_{\mathrm{T}}$, and inspiratory times that result in delivery of less inhaled drug to the lungs. Improvements in nebulizer technology have provided better delivery options for pediatric patients. A resting non-distressed patient is more likely to receive an effective treatment than a patient who is crying or screaming. Nebulizer treatment should be provided with a well-fitted front-loaded face mask in patients who do not tolerate a mouthpiece. Blow-by therapy is ineffective in infants, but a jet nebulizer with an infant hood is a good alternative. pMDIs with VHCs are as efficient as jet nebulizers and have provided similar outcomes in infants and children but with wider acceptance and potentially fewer side effects.

HFNC delivery of aerosolized drugs may be effective, but there are differences in drug delivery related to the system being used. Its safety needs to be assessed in humans. Infant nasal CPAP administration of inhaled agents remains a challenge, with only minimal drug deposited in vitro. Placement of the nebulizer in these systems is device-dependent. New vibrating mesh nebulizer devices can be integrated into full face masks during pediatric NIV. If these nebulizers or masks are unavailable, a vi- 
brating mesh nebulizer should be placed as close to the patient as possible and after the exhalation valve.

Vibrating mesh nebulizers represent a safer and more efficient alternative for drug delivery during infant and small pediatric ventilation, but are far more costly than gas-powered jet nebulizers. Nebulizers appear to be more efficient placed at the humidifier during pediatric mechanical ventilation. However, the nebulizer may be more efficient placed proximal to the patient Y-piece than before the humidifier during infant ventilation, especially with a ventilator bias flow of $\geq 2 \mathrm{~L} / \mathrm{min}$. Studies from in vitro lung models have shown that drug delivery with a vibrating mesh nebulizer is greater during HFOV than during conventional neonatal and pediatric mechanical ventilation.

\section{REFERENCES}

1. Amirav I, Newhouse MT. Deposition of small particles in the developing lung. Paediatr Respir Rev 2012;13(2):73-78.

2. Xi J, Si X, Zhou Y, Kim J, Berlinski A. Growth of nasal and laryngeal airways in children: implications in breathing and inhaled aerosol dynamics. Respir Care 2014;59(2):263-273.

3. DiBlasi RM, Richardson CP, Hansen T. Pulmonary physiology of the newborn. In: Gleason A, Devasker S, editors. Avery's diseases of the newborn, 9th edition. Philadelphia: Saunders; 2012:44-4144-13.

4. Amirav I, Borojeni AA, Halamish A, Newhouse MT, Golshahi L. Nasal versus oral aerosol delivery to the lungs in infants and toddlers. Pediatr Pulmonol 2015;50(3):276-283.

5. Martin RJ, Miller MJ, Siner B, DiFiore JM, Carlo WA. Effects of unilateral nasal occlusion on ventilation and pulmonary resistance in infants. J Appl Physiol 1989;66(6):2522-2526.

6. Salmon B, Wilson NM, Silverman M. How much aerosol reaches the lungs of wheezy infants and toddlers? Arch Dis Child 1990; 65(4):401-403.

7. Mallol J, Rattray S, Walker G, Cook D, Robertson CF. Aerosol deposition in infants with cystic fibrosis. Pediatr Pulmonol 1996; 21(5):276-281.

8. Chua HL, Collis GG, Newbury AM, Chan K, Bower GD, Sly PD, Le Souef PN. The influence of age on aerosol deposition in children with cystic fibrosis. Eur Respir J 1994;7(12):2185-2191.

9. Amirav I, Balanov I, Gorenberg M, Luder AS, Newhouse MT, Groshar D. Beta-agonist aerosol distribution in respiratory syncytial virus bronchiolitis in infants. J Nucl Med 2002;43(4):487-491.

10. Erzinger S, Schueepp KG, Brooks-Wildhaber J, Devadason SG, Wildhaber JH. Facemasks and aerosol delivery in vivo. J Aerosol Med 2007;20(Suppl 1):S78-S83; discussion S83-S84.

11. Tal A, Golan H, Grauer N, Aviram M, Albin D, Quastel MR. Deposition pattern of radiolabeled salbutamol inhaled from a metered-dose inhaler by means of a spacer with mask in young children with airway obstruction. J Pediatr 1996;128(4):479-484.

12. Svartengren M, Svartengren K, Aghaie F, Philipson K, Camner P. Lung deposition and extremely slow inhalations of particles. Limited effect of induced airway obstruction. Exp Lung Res 1999; 25(4):353-366.

13. Newhouse MT, Hirst PH, Duddu SP, Walter YH, Tarara TE, Clark AR, Weers JG. Inhalation of a dry powder tobramycin PulmoSphere formulation in healthy volunteers. Chest 2003;124(1):360366.
14. Corcoran TE, Niven R, Verret W, Dilly S, Johnson BA. Lung deposition and pharmacokinetics of nebulized cyclosporine in lung transplant patients. J Aerosol Med Pulm Drug Deliv 2014;27(3): 178-184.

15. Corcoran TE, Devadason SG, Kuehl PJ. Introduction: aerosol delivery of orally inhaled agents. J Aerosol Med Pulm Drug Deliv 2012;25(Suppl 1):S3-S5.

16. Fink JB. Aerosol delivery to ventilated infant and pediatric patients. Respir Care 2004;49(6):653-665.

17. Ari A, Restrepo RD, American Association for Respirator Care. Aerosol delivery device selection for spontaneously breathing patients: 2012. Respir Care 2012;57(4):613-626.

18. Myers TR. The science guiding selection of an aerosol delivery device. Respir Care 2013;58(11):1963-1973.

19. Gadomski AM, Scribani MB. Bronchodilators for bronchiolitis. Cochrane Database Syst Rev 2014;6:CD001266.

20. Hardy JG, Newman SP, Knoch M. Lung deposition from four nebulizers. Respir Med 1993;87(6):461-465.

21. Lødrup Carlsen KC, Nikander K, Carlsen KH. How much nebulized budesonide reaches infants and toddlers? Arch Dis Child 1992; 67(9):1077-1079.

22. Tiemersma S, Minocchieri S, van Lingen RA, Nelle M, Devadason SG. Vibrating membrane devices deliver aerosols more efficiently than standard devices: a study in a neonatal upper airway model. J Aerosol Med Pulm Drug Deliv 2013;26(5):280-286.

23. El Taoum KK, Xi J, Kim JW, Berlinski A. In vitro evaluation of aerosols delivered via the nasal route. Respir Care 2015 [Epub ahead of print] doi: 10.4187/respcare.03606.

24. Lin HL, Wan GH, Chen YH, Fink JB, Liu WQ, Liu KY. Influence of nebulizer type with different pediatric aerosol masks on drug deposition in a model of a spontaneously breathing small child. Respir Care 2012;57(11):1894-1900.

25. Ari A, Dornelas de Andrade A, Sheard M, Al Hamad B, Fink JB. Performance comparisons of jet and mesh nebulizers using different interfaces in simulated spontaneously breathing adults and children. J Aerosol Med Pulm Drug Deliv 2014 [Epub ahead of print] doi: 10.1089/jamp.2014.1149.

26. Ditcham W, Murdzoska J, Zhang G, Roller C, von Hollen D, Nikander K, Devadason SG. Lung deposition of ${ }^{99 \mathrm{~m}}$ Tc-radiolabeled albuterol delivered through a pressurized metered dose inhaler and spacer with facemask or mouthpiece in children with asthma. J Aerosol Med Pulm Drug Deliv 2014;27(Suppl 1):S63-S75.

27. Usmani OS, Biddiscombe MF, Barnes PJ. Regional lung deposition and bronchodilator response as a function of $\beta_{2}$-agonist particle size. Am J Respir Crit Care Med 2005;172(12):1497-1504.

28. Amirav I, Newhouse MT. Aerosol therapy with valved holding chambers in young children: importance of the facemask seal. Pediatrics 2001;108(2):389-394.

29. Shah SA, Berlinski AB, Rubin BK. Force-dependent static dead space of face masks used with holding chambers. Respir Care 2006; 51(2):140-144.

30. Janssens HM, Tiddens HA. Facemasks and aerosol delivery by metered dose inhaler-valved holding chamber in young children: a tight seal makes the difference. J Aerosol Med 2007;20(Suppl 1): S59-S63; discussion S63-S65.

31. Ari A, Fink JB. Effective bronchodilator resuscitation of children in the emergency room: device or interface? Respir Care 2011;56(6): 882-885.

32. Amirav I, Mansour Y, Mandelberg A, Bar-Ilan I, Newhouse MT. Redesigned face mask improves "real life" aerosol delivery for Nebuchamber. Pediatr Pulmonol 2004;37(2):172-177.

33. Turpeinen M, Nikander K, Malmberg LP, Pelkonen A. Metered dose inhaler add-on devices: is the inhaled mass of drug depen- 
dent on the size of the infant? J Aerosol Med 1999;12(3):171176.

34. Chavez A, McCracken A, Berlinski A. Effect of face mask dead volume, respiratory rate and tidal volume on inhaled albuterol delivery. Pediatr Pulmonol 2010;45(3):224-229.

35. Lin HL, Restrepo RD, Gardenhire DS, Rau JL. Effect of face mask design on inhaled mass of nebulized albuterol, using a pediatric breathing model. Respir Care 2007;52(8):1021-1026.

36. Smaldone GC, Berg E, Nikander K. Variation in pediatric aerosol delivery: importance of facemask. J Aerosol Med 2005;18(3):354363.

37. Sangwan S, Gurses BK, Smaldone GC. Facemasks and facial deposition of aerosols. Pediatr Pulmonol 2004;37(5):447-452.

38. Mansour MM, Smaldone GC. Blow-by as potential therapy for uncooperative children: an in-vitro study. Respir Care 2012;57(12): 2004-2011.

39. Nikander K, Berg E, Smaldone GC. Jet nebulizers versus pressurized metered-dose inhalers with valved holding chambers: effects of the facemask on aerosoldelivery. J Aerosol Med 2007;20(Suppl 1):S46-S55; discussion S55-S58.

40. Amirav I, Newhouse MT, Luder A, Halamish A, Omar H, Gorenberg M. Feasibility of aerosol drug delivery to sleeping infants: a prospective observational study. BMJ Open 2014;4(3):e004124.

41. Amirav I, Balanov I, Gorenberg M, Groshar D, Luder AS. Nebulizer hood compared to mask in wheezy infants: aerosol therapy without tears! Arch Dis Child 2003;88(8):719-723.

42. Kim J, Xi J, Si X, Berlinski A, Su WC. Hood nebulization: effects of head direction and breathing mode on particle inhalability and deposition in a 7-month-old infant model. J Aerosol Med Pulm Drug Deliv 2014;27(3):209-218.

43. Kugelman A, Amirav I, Mor F, Riskin A, Bader D. Hood versus mask nebulization in infants with evolving bronchopulmonary dysplasia in the neonatal intensive care unit. J Perinatol 2006;26(1): 31-36.

44. Amirav I, Oron A, Tal G, Cesar K, Ballin A, Houri S, et al. Aerosol delivery in respiratory syncytial virus bronchiolitis: hood or face mask? J Pediatr 2005;147(5):627-631.

45. te Pas AB, Wong C, Kamlin CO, Dawson JA, Morley CJ, Davis PG. Breathing patterns in preterm and term infants immediately after birth. Pediatr Res 2009;65(3):352-356.

46. Wise PH, Krauss AN, Waldman S, Auld PA. Flow-volume loops in newborn infants. Crit Care Med 1980;8(2):61-63.

47. Iles R, Lister P, Edmunds AT. Crying significantly reduces absorption of aerosolized drug in infants. Arch Dis Child 1999;81(2):163165 .

48. Murakami G, Igarashi T, Adachi Y, Matsuno M, Adachi Y, Sawai $\mathrm{M}$, et al. Measurement of bronchial hyperreactivity in infants and preschool children using a new method. Ann Allergy 1990;64(4): 383-387.

49. Baty R. Blow-by revisited. Respir Care 2008;53(7):920-921; author reply 921-922.

50. Rubin BK. Bye-bye, blow-by. Respir Care 2007;52(8):981.

51. Everard ML, Clark AR, Milner AD. Drug delivery from jet nebulisers. Arch Dis Child 1992;67(5):586-591.

52. Restrepo RD, Dickson SK, Rau JL, Gardenhire DS. An investigation of nebulized bronchodilator delivery using a pediatric lung model of spontaneous breathing. Respir Care 2006;51(1):56-61.

53. Wildhaber JH, Devadason SG, Eber E, Hayden MJ, Everard ML, Summers QA, LeSouëf PN. Effect of electrostatic charge, flow, delay and multiple actuations on the in vitro delivery of salbutamol from different small volume spacers for infants. Thorax 1996;51(10): 985-988.
54. Bisgaard H, Anhøj J, Wildhaber JH. Spacer devices. In: Bisgaard $\mathrm{H}$, O'Callaghan C, Smaldone GC, editors. Drug delivery to the lung. New York: Marcel Dekker; 2002:389-420.

55. Rau JL, Coppolo DP, Nagel MW, Avvakoumova VI, Doyle CC, Wiersema KJ, Mitchell JP. The importance of nonelectrostatic materials in holding chambers for delivery of hydrofluoroalkane albuterol. Respir Care 2006;51(5):503-510.

56. Coppolo DP, Mitchell JP, Nagel MW. Levalbuterol aerosol delivery with a nonelectrostatic versus a nonconducting valved holding chamber. Respir Care 2006;51(5):511-514.

57. Minai BA, Martin JE, Cohn RC. Results of a physician and respiratory therapist collaborative effort to improve long-term metered dose inhaler technique in a pediatric asthma clinic. Respir Care 2004;49(6):600-605.

58. Cotterell EM, Gazarian M, Henry RL, O'Meara MW, Wales SR. Child and parent satisfaction with the use of spacer devices in acute asthma. J Paediatr Child Health 2002;38(6):604-607.

59. Fok TF, Monkman S, Dolovich M, Gray S, Coates G, Paes B, et al. Efficiency of aerosol medication delivery from a metered dose inhaler versus jet nebulizer in infants with bronchopulmonary dysplasia. Pediatr Pulmonol 1996;21(5):301-309.

60. DiBlasi RM, Coppolo DP, Nagel MW, Doyle CC, Avvakoumova VI, Ali RS, Mitchell JP. A novel, versatile valved holding chamber for delivering inhaled medications to neonates and small children: laboratory simulation of delivery options. Respir Care 2010;55(4): 419-426.

61. Delgado A, Chou KJ, Silver EJ, Crain EF. Nebulizers vs. metered dose inhalers with spacers for bronchodilator therapy to treat wheezing in children aged 2 to 24 months in a pediatric emergency department. Arch Pediatr Adolesc Med 2003;157(1):76-80.

62. Leversha AM, Campanella SG, Aickin RP, Asher MI. Cost and effectiveness of spacer versus nebulizer in young children with moderate to severe acute asthma. J Pediatr 2000;136(4):497-502.

63. Deerojanawong J, Manuyakorn W, Prapphal N, Harnruthakorn C, Sritippayawan S, Samransamruajkit R. Randomized controlled trial of salbutamol aerosol therapy via metered dose inhaler-spacer vs. jet nebulizer in young children with wheezing. Pediatr Pulmonol 2005;39(5):466-472.

64. Osmond M, Diner B. Evidence-based emergency medicine. Nebulizers versus inhalers with spacers for acute asthma in pediatric patients. Ann Emerg Med 2004;43(3):413-415.

65. Ploin D, Chapuis FR, Stamm D, Robert J, David L, Chatelain PG, et al. High-dose albuterol by meter-dose inhaler plus a spacer device versus nebulization in preschool children with recurrent wheezing: a double blind, randomized equivalence trial. Pediatrics 2000; 106(2 Pt 1):311-317.

66. Kerem E, Levison H, Schuh S, O'Brodovich H, Reisman J, Bentur L, Canny GJ. Efficacy of albuterol administered by nebulizer versus spacer device in children with acute asthma. J Pediatr 1993; 123(2):313-317.

67. Cates CJ, Bara A, Crilly JA, Rowe BH. Holding chambers versus nebulisers for beta-agonist treatment of acute asthma. Cochrane Database Syst Rev 2003;3:CD000052.

68. Castro-Rodriguez JA, Rodrigo GJ. Beta-agonists through metered dose inhaler with valved holding chamber versus nebulizer for acute exacerbation of wheezing or asthma in children under 5 years of age: a systematic review with meta-analysis. J Pediatr 2004;145(2): 172-177.

69. Cates CJ, Welsh EJ, Rowe BH. Holding chambers (spacers) versus nebulisers for beta-agonist treatment of acute asthma. Cochrane Database Syst Rev 2013;9:CD000052.

70. Salyer JW, DiBlasi RM, Crotwell DN, Cowan CA, Carter ER. The conversion to metered-dose inhaler with valved holding 
chamber to administer inhaled albuterol: a pediatric hospital experience. Respir Care 2008;53(3):338-345.

71. Krebs SE, Flood RG, Peter JR, Gerard JM. Evaluation of a highdose continuous albuterol protocol for treatment of pediatric asthma in the emergency department. Pediatr Emerg Care 2013;29(2):191196.

72. Camargo CA Jr, Spooner CH, Rowe BH. Continuous versus intermittent beta-agonists in the treatment of acute asthma. Cochrane Database Syst Rev 2003;(4):CD001115.

73. Kim IK, Phrampus E, Venkataraman S, Pitetti R, Saville A, Corcoran $\mathrm{T}$, et al. Helium/oxygen-driven albuterol nebulization in the treatment of children with moderate to severe asthma exacerbations: a randomized, controlled trial. Pediatrics 2005;116(5):11271133.

74. Levitt MA, Gambrioli EF, Fink JB. Comparative trial of continuous nebulization versus metered-dose inhaler in the treatment of acute bronchospasm. Ann Emerg Med 1995;26(3):273-277.

75. Bhashyam AR, Wolf MT, Marcinkowski AL, Saville A, Thomas K, Carcillo JA, Corcoran TE. Aerosol delivery through nasal cannulas: an in vitro study. J Aerosol Med Pulm Drug Deliv 2008;21(2):181188.

76. Ari A, Harwood R, Sheard M, Dailey P, Fink JB. In vitro comparison of heliox and oxygen in aerosol delivery using pediatric high flow nasal cannula. Pediatr Pulmonol 2011;46(8):795-801.

77. Kearney CN, Crotwell DN, van Well J, Gommers E, Shen S, Zheng $\mathrm{J}$, et al. Influence of patient interface and gas composition on albuterol delivery in a spontaneously breathing infant and child model: a bench study (abstract). Respir Care 2014;59(10):OF30.

78. Perry SA, Kesser KC, Geller DE, Selhorst DM, Rendle JK, Hertzog $\mathrm{JH}$. Influences of cannula size and flow rate on aerosol drug delivery through the Vapotherm humidified high-flow nasal cannula system. Pediatr Crit Care Med 2013;14(5):e250-e256.

79. Smedsaas-Löfvenberg A, Nilsson K, Moa G, Axelsson I. Nebulization of drugs in a nasal CPAP system. Acta Paediatr 1999;88(1): 89-92.

80. Sunbul FS, Fink JB, Harwood R, Sheard MM, Zimmerman RD, Ari A. Comparison of HFNC, bubble CPAP and SiPAP on aerosol delivery in neonates: an in-vitro study. Pediatr Pulmonol 2014 [Epub ahead of print] doi: 10.1002/ppul.23123.

81. Farney KD, Kuehne BT, Gibson LA, Nelin LD, Shepherd EG. In vitro evaluation of radio-labeled aerosol delivery via a variableflow infant CPAP system. Respir Care 2014;59(3):340-344.

82. Abdelrahim ME, Plant P, Chrystyn H. In-vitro characterisation of the nebulised dose during non-invasive ventilation. J Pharm Pharmacol 2010;62(8):966-972.

83. Branconnier MP, Hess DR. Albuterol delivery during noninvasive ventilation. Respir Care 2005;50(12):1649-1653.

84. White CC, Crotwell DN, Shen S, Salyer J, Yung D, Zheng J, DiBlasi RM. Bronchodilator delivery during simulated pediatric noninvasive ventilation. Respir Care 2013;58(9):1459-1466.

85 . Hintz SR. Pharmacology review: bronchodilator therapy in the preterm infant. NeoReviews 2003;4(9):e245-e249.

86. Sosulski R, Abbasi S, Bhutani VK, Fox WW. Therapeutic value of terbutaline in bronchopulmonary dysplasia. Pediatr Pulmonol 1986; 2(5);269-273.

87. Gappa M, Gärtner M, Poets CF, von der Hardt H. Effects of salbutamol delivery from a metered dose inhaler versus jet nebuliser on dynamic lung mechanics in very preterm infants with chronic lung disease. Pediatr Pulmonol 1997;23(6):442-448.
88. Bindl L, Fahnenstich H, Peukert U. Aerosolized prostacyclin for pulmonary hypertension in neonates. Arch Dis Child Fetal Neonatal Ed 1994;71(3):F214-F216.

89. Yilmaz O, Kahveci H, Zeybek C, Ciftel M, Kilic O. Inhaled iloprost in preterm infants with severe respiratory distress syndrome and pulmonary hypertension. Am J Perinatol 2014;31(4):321-326.

90. Carroll CL, Backer CL, Mavroudis C, Cook K, Goodman DM. Inhaled prostacyclin following surgical repair of congenital heart disease—a pilot study. J Card Surg 2005;20(5):436-439.

91. Lampland AL, Wolfson MR, Mazela J, Henderson C, Gregory TJ, Meyers P, et al. Aerosolized KL4 surfactant improves shortterm survival and gas exchange in spontaneously breathing newborn pigs with hydrochloric acid-induced acute lung injury. Pediatr Pulmonol 2014;49(5):482-489.

92. Diblasi RM. Clearing the mist from our eyes: bronchodilators, mechanical ventilation, new devices, locations, and what you should know about bias flow. Respir Care 2010;55(7):942-946.

93. Ballard J, Lugo RA, Salyer JW. A survey of albuterol administration practices in intubated patients in the neonatal intensive care unit. Respir Care 2002;47(1):31-38.

94. Salyer JW. Manual resuscitators: some inconvenient truths. Respir Care 2009;54(12):1638-1643.

95. Lin HL, Fink JB, Zhou Y, Cheng YS. Influence of moisture accumulation in inline spacer on delivery of aerosol using metered-dose inhaler during mechanical ventilation. Respir Care 2009;54(10):13361341.

96. Grigg J, Arnon S, Jones T, Clarke A, Silverman M. Delivery of therapeutic aerosols to intubated babies. Arch Dis Child 1992;67(1 Spec No):25-30.

97. Miller DD, Amin MM, Palmer LB, Shah AR, Smaldone GC. Aerosol delivery and modern mechanical ventilation: in vitro/in vivo evaluation. Am J Respir Crit Care Med 2003;168(10):1205-1209.

98. Dhand R, Mercier E. Effective inhaled drug administration to mechanically ventilated patients. Expert Opin Drug Deliv 2007;4(1):47-61.

99. Ehtezazi T, Turner MA. The application of mechanical aerosol delivery systems in an in vitro model of mechanically ventilated neonates. Recent Pat Drug Deliv Formul 2013;7(3):174-183.

100. Flavin M, MacDonald M, Dolovich M, Coates G, O'Brodovich H. Aerosol delivery to the rabbit lung with an infant ventilator. Pediatr Pulmonol 1986;2(1):35-39.

101. Fok TF, Al-Essa M, Monkman S, Dolovich M, Girard L, Coates G, Kirpalani H. Pulmonary deposition of salbutamol aerosol delivered by metered dose inhaler, jet nebulizer, and ultrasonic nebulizer in mechanically ventilated rabbits. Pediatr Res 1997;42(5):721-727.

102. Cameron D, Arnot R, Clay M, Silverman M. Aerosol delivery in neonatal ventilator circuits: a rabbit lung model. Pediatr Pulmonol 1991;10(3):208-213.

103. Dubus JC, Vecellio L, De Monte M, Fink JB, Grimbert D, Montharu $\mathrm{J}$, et al. Aerosol deposition in neonatal ventilation. Pediatr Res 2005;58(1):10-14.

104. Ari A, Atalay OT, Harwood R, Sheard MM, Aljamhan EA, Fink JB. Influence of nebulizer type, position, and bias flow on aerosol drug delivery in simulated pediatric and adult lung models during mechanical ventilation. Respir Care 2010;55(7):845-851.

105. Cooper DS, Schwartz SM, Raake JL, Beam AR, Nelson DP. Supplemental inhaled gases alter tidal volume delivery and measurement. Pediatr Crit Care Med 2005;6(2):150-153.

106. Ari A, Areabi H, Fink JB. Evaluation of aerosol generator devices at 3 locations in humidified and non-humidified circuits during adult mechanical ventilation. Respir Care 2010;55(7):837-844. 
107. Berlinski A, Willis JR. Albuterol delivery by 4 different nebulizers placed in 4 different positions in a pediatric ventilator in vitro model. Respir Care 2013;58(7):1124-1133.

108. DiBlasi RM, Shen S, Crotwell D, Salyer J, Mahaffey T, Yung D. Iloprost drug delivery during infant mechanical ventilation: influence of nebulizer position during conventional and high frequency ventilation (abstract). Respir Care 2013;57(10):1774.

109. Parker DK, Shen S, Zhiang J, Ivy DD, Yung D, DiBlasi RM. Inhaled treprostinil using a vibrating mesh nebulizer in mechanically ventilated adult, pediatric, and infant lung models (abstract). Respir Care 2014;59(10):OF6.

110. Mazela J, Chmura K, Kulza M, Henderson C, Gregory TJ, Moskal A, et al. Aerosolized albuterol sulfate delivery under neonatal ventilatory conditions: in vitro evaluation of a novel ventilator circuit patient interface connector. J Aerosol Med Pulm Drug Deliv 2014;27(1):58-65.

111. Garner SS, Wiest DB, Bradley JW. Albuterol delivery by metereddose inhaled in a pediatric high-frequency oscillatory ventilation mode. Crit Care Med 2000;28(6):2086-2089.

112. Sood BG, Peterson J, Malian M, Galli R, Geisor-Walter M, McKinnon $\mathrm{J}$, et al. Jet nebulization of prostaglandin $\mathrm{E}_{1}$ during neonatal mechanical ventilation: stability, emitted dose and aerosol particle size. Pharmacol Res 2007;56(6):531-541.

113. Sood BG, Latif Z, Shen Y, Galli RJ, Dunlap CW, Gelmini MJ, Haacke EM. Aerosol delivery during high frequency jet ventilation: an MRI evaluation. Respir Care 2012;57(11):1901-1907.

\section{Discussion}

Berlinski: I'll try to be brief, but I'll start with acknowledging the reality of some data you showed about cost that would probably not hold true today. The reason for that is that in 2005, pMDIs were dirt cheap, and today they are very expensive, so it's a conundrum. We know that we ask patients to use a pMDI with a spacer at home, but when they come to the hospital and are sick, we give them a nebulizer with albuterol because it's less expensive. This is the reality, I think, in every single hospital today in the pediatric world. I would challenge you to redo your numbers with today's costs, and you'll find that it's extremely expensive. The other day, I was buying some MDIs for my lab, and when I saw the bill, I was really surprised. I wasn't aware of how expensive they had become. So that's something we'll have to acknowledge, that it probably works well and is consistent with what we tell patients to do at home, but the reality is going to be that you might not be able to implement that because of cost issues. Also, you talked about different masks, and as we've said already, a nebulizer is not a nebulizer is not a nebulizer-the same goes for masks. The configuration of the masks, whether it's a bottom- or front-loading aerosol, is very important, and it makes a difference. I have always been a skeptic about using blow-by or some aerosol to the face; I said we don't have the right model. At the last American Thoracic
Society meeting, we presented data using an anatomically correct model with a front-loaded face mask placed $2 \mathrm{~cm}$ from the face, and to my surprise, we found some drug delivery. So, I think that now we might need to reconsider some of the things we always said will work. However, a bench study is just a bench study; a patient moves and doesn't sit and wait for the stream to be aligned. The other thing that we noticed was that minimum variations of the stream to the face made a significant difference in the amount of drug delivered.

DiBlasi: Yes, we continue to administer $90 \%$ of our intermittent inhaled bronchodilators with a pMDI/spacer. We have decent outcomes, and the patients and families seem happy to use a device they are familiar with, tolerate better, and is potentially more effective than a smallvolume neb. The price of albuterol is ridiculous. I would love to revisit our cost models using albuterol hydrofluoroalkane (HFA). Cost drives major decisions these days, and we have often thought about switching back to smallvolume nebs. Regarding your other question about blow-by and different masks, it's very difficult to mimic exactly what's going on clinically with a bench test. Anatomically accurate face and airway models, as well as new face mask designs, have introduced a whole new list of research questions for me. Science is iterative, so it is worth repeating studies using the latest research technology. I think that, especially with our lung models nowadays, we might want to mimic erratic breathing. We have the ability to configure these test lung models to do just about anything: cough, panic, forced exhalation, hyperpnea, and hypopnea. So it might be nice to look at these factors and other factors within the environment. I have always noticed that smaller kids move around a lot during treatments. I have attached one of my head models to an oscillating fan to mimic this scenario. Our next step is to compare different types of large-volume continuous nebulizers with other devices out there like the Aerogen, with a continuous albuterol drip hooked up to it, using these realistic models.

Willson: Rob [DiBlasi], thank you. I'm convinced that Richmond is the asthma capital of the world. Working in the pediatric ICU (PICU), we have a large number of kids coming in, and the criteria for coming into the PICU is continuous nebulized albuterol. Those are the ones who have to come to the PICU, and after your presentation, I'm wondering several things. Are there more efficient ways to do that than giving the continuous jet aerosol? Would the Aerogen, for example, be a better way to deliver more drug more quickly? The other concern-and it's more theoretical, I suppose-is we think we're delivering aerosol into the airway when we're taking care of these kids in the ICU. The limiting factor for albuterol is heart rate, really. We'll jack up 
however much we're giving until their heart rate goes up. Are we getting systemic absorption and therefore really not doing what we think we're doing? Would intravenous salbutamol, for example, which is available in Europe, do just as well? Or are we really getting an effect on the airways? So, 2 questions: first, what is the most efficient way to deliver albuterol? This is an everyday common problem, at least where I practice. Second, are we fooling ourselves into thinking we're delivering the aerosol into the airways and having a direct effect on the small airways, or are we just getting systemic absorption?

DiBlasi: Excellent question. I think there are other ways to provide highdose albuterol to patients. One thing I mentioned is breath-actuated nebulizers. You don't have to do it as frequently; there's the potential for less systemic absorption. I think that the high heart rate you're seeing really has a lot to do with oral impaction. There are inconsistencies in the particle size in the different devices, and it's likely that they're providing larger particles, and that's probably why we' re seeing the heart rates jacked way up to 210 beats/min in 8- and 9-year olds, which scares me a little bit. We should also compare particle size and deposition with the Aerogen in continuous administration mode for patients. In theory, a device that delivers more particles within the respirable particle range would be better because less oral impaction may result in less systemic absorption. But these kids stay on continuous nebulizers for hours, so we may never know for sure the cause of their tachycardia. I think that would definitely be a good dependent variable to assess and address as we move forward with conducting studies and enrolling subjects.

Willson: Are we affecting actual direct airway $\beta$-agonist [receptors], or are we basically getting systemic absorption and the effect that way?
DiBlasi: I think that's difficult to tell because there aren't any objective data we can obtain from patients other than some really nice radiographic techniques (scintigraphy). It's very difficult to do a pulmonary function test (PFT) on a kid who's receiving bronchodilators continuously. They have poor lung function and aren't really going to coordinate with or tolerate PFTs, so I think it's very difficult to answer that question. It's likely that patients in the emergency department are not getting much albuterol delivered where it needs to be during continuous nebulization. I think a lot of that also has to do with the fact that, again, you're providing drug throughout the entire respiratory cycle, and the particle size needs to be investigated further and compared with other devices that have potential in these acute situations.

Willson: Would it be better to give these kids-rather than have them come up on continuous albuterolfrequent MDIs?

DiBlasi: We discussed that in our emergency department because our nurses know how to give pMDIs with spacers, and nurses are sometimes the first ones there to provide rescue drugs. We know it's an effective way to give bronchodilators, so then what dose would we use? That's the question that always comes up. Do we give 10 puffs? Twenty puffs? It's hard to compare apples to oranges, with one being pMDIs with spacers and the other being continuous nebulizers. How much? You give them as much as possible. I do believe that a pMDI with a spacer at a high dose could be as effective if not slightly more effective than a continuous nebulizer and better tolerated with fewer adverse effects.

Berlinski: I think the trick with continuous albuterol is to really have a good interface with the patient. That's really what makes a significant difference. For somebody who is extremely sick, I would probably not use a pMDI, and I would say that we use a lot of pMDIs at my institution. If you think about respiratory therapy time, you're going to give 10 puffs, which is about 15 min of work, at least. The data we were talking about earlier—mask leaks and loss of drugs - are for pMDIs, and people are extrapolating them to nebulizers. Nebulizers are a continuous burst of aerosol, so if you remove your mask for 5 seconds, you lose those 5 seconds. If you remove your mask from the pMDI and spacer when it is actuated, you lose that puff. You have to think in that regard, and for severe patients, I consider continuous albuterol to probably be a better choice. In fact, at Rob's institution, the asthma pathway has continuous albuterol for the more severe patients from the getgo, which we don't do at ours because the cost is higher compared with a small-volume nebulizer.

DiBlasi: With all due respect, providing continuous nebulization to children requires a patient to tolerate a mask that is kept in place during the continuous treatment. For someone who may not be standing down there holding the mask on their face for the aerosol treatments, this may sound easy. For me, as a therapist who may actually be down there doing this, it sounds so much easier and attractive to use an intermittent high-dose pMDI/ spacer with a face mask in these patients. It really does. I think that we definitely need to investigate these treatment options because it's easier, and frankly, you can have job satisfaction as a result.

O'Malley: Thank you for your presentation. You now have more pMDI use in your institution, so what is your policy for wait time between actuations? Do you have one?

DiBlasi: Yes. We usually wait 30 seconds. 
O'Malley: So 30 seconds between every puff?

DiBlasi: We wait 30 seconds. I think that if you look at the American Association for Respiratory Care Clinical Practice Guideline, they suggest waiting 30 seconds between actuations.

O'Malley: I thought the recommendation is 1 minute for albuterol.

$\dagger$ Fink: That was partially because of the chlorofluorocarbons (CFCs) that cooled the canister with each dose, requiring some time to warm back up. With the new HFAs, it's less of an issue. But there was a paper in 1996 where we looked at priming and actuation, and we found that as long as you wait at least 15 seconds (this is with the old CFCs), we didn't have a change in particle size.

O'Malley: Was that published?

\section{$\dagger$ Fink: Yes.}

Berlinski: The reality is that the package insert says 1 minute. It says 1 minute for all of them. There was a study a couple years ago presented in Europe that showed some changes in small-particle size when you vary the time between actuations. This summer, we are doing a similar study in our lab and looking at different intervals between pMDIs. But I think what Cathy [O'Malley] is really alluding to is the time it takes you to give 10 puffs and being able to present that as a financial advantage as opposed to using a mask with a nebulizer. I think a lot of places are asking for the data. I don't think we can extrapolate CFC data to HFA because these are not the same. $\dagger$ Fink: Good point. Arzu's group (one of her students) came up with a study ${ }^{1}$ looking at simulating infant breathing with aerosol delivered via a mask with a jet nebulizer or pMDI versus administration of aerosol during HFNC with a mask and pMDI over the cannula. They reported a huge reduction in aerosol with the mask compared with HFNC. That partially makes sense because you're giving high-flow $\mathrm{O}_{2}$, and it's blowing gas and aerosol out of this obligate nose breather's nose. That is one of the reasons that for HFNC, if you can get aerosol in through the cannula and you don't have to interrupt the pressure and the flow, it might have some advantages.

DiBlasi: I wonder, in these studies, have you observed a tremendous amount of fluid condensate building up on the inner walls of these cannulas that could potentially go down into the lung and be aspirated? We've had issues on the floor with kids being treated with HFNC without nebulizers, and there's a tremendous amount of-depending on your humidifier settings and the device you're using-juice that gets into the cannula. We had a near-sentinel event that occurred because a kid had a bunch of fluid that was thrown down into the nasopharynx, it occluded his airway, and he was very unstable. My question is, when you do these aerosol studies, obviously you're looking at the interfaces, and are there differences in fluid accumulation from aerosols between them?

$\dagger$ Fink: Great question. In fact, one of the reasons that we started putting the nebulizer before the humidifier was to rain out the big particles from the aerosol. That doesn't necessarily take care of the condensate if you're not using a heated wire that's really well controlled. Our criterion is that we like to get it set so that we don't have more than a little blurp of water coming out of the cannula more than about once per minute. The folks in North Carolina who developed their system for patients with cystic fibrosis actually don't add humidity. They use about $2 \mathrm{~L} / \mathrm{min}$ and really reduce aerosol rainout pre-cannula so that they don't have any of those droplets coming up, and they've got it down to one every couple of minutes.

DiBlasi: You mentioned the humidifier acting as a potential filter for the larger particles. With ventilators, there are differences in locations in the ventilator circuit. Is there the potential to study that and place the nebulizer in different locations during HFNC? Has that been done?

Ari: Yes, one of our graduate students at Georgia State University compared aerosol delivery via HFNC, bubble CPAP, and SiPAP in a simulated spontaneously breathing premature infant model using 2 different nebulizer positions: (1) proximal to the patient and (2) before the humidifier. The findings of our study showed that placement of the mesh nebulizer before the humidifier increased aerosol drug delivery with all devices tested in the study. Recently, our paper was accepted for publication by Pediatric Pulmonology.

$\dagger$ James B Fink PhD RRT FAARC, James B Fink LLC, San Mateo, California, and Division of Respiratory Therapy, Georgia State University, Atlanta, Georgia, representing Aerogen.

\section{REFERENCE}

1. Alalwan MA, Ari A, Fink J, Harwood R, Bryant L, Sheard M. Delivery of albuterol by pressurized metered-dose inhaler and jet nebulizer via mask with high-flow nasal cannula in place reduces aerosol delivery. Respir Care 2012;57(10):1702. 